\title{
Effects of polar stratospheric clouds in the Nimbus 7 LIMS Version 6 data set
}

\author{
Ellis Remsberg $^{1}$ and V. Lynn Harvey ${ }^{2,3}$ \\ ${ }^{1}$ Science Directorate, NASA Langley Research Center, 21 Langley Blvd, Mail Stop 401B, Hampton, \\ Virginia 23681, USA \\ ${ }^{2}$ Laboratory for Atmospheric and Space Physics, University of Colorado Boulder, 3665 Discovery Drive, \\ Boulder, CO 80303, Colorado, USA \\ ${ }^{3}$ Department of Atmospheric and Oceanic Sciences, University of Colorado Boulder, Boulder, Colorado, USA \\ Correspondence to: Ellis Remsberg (ellis.e.remsberg@nasa.gov)
}

Received: 24 March 2016 - Published in Atmos. Meas. Tech. Discuss.: 7 April 2016

Revised: 6 June 2016 - Accepted: 14 June 2016 - Published: 12 July 2016

\begin{abstract}
The historic Limb Infrared Monitor of the Stratosphere (LIMS) measurements of 1978-1979 from the Nimbus 7 satellite were re-processed with Version 6 (V6) algorithms and archived in 2002. The V6 data set employs updated radiance registration methods, improved spectroscopic line parameters, and a common vertical resolution for all retrieved parameters. Retrieved profiles are spaced about every $1.6^{\circ}$ of latitude along orbits and include the additional parameter of geopotential height. Profiles of $\mathrm{O}_{3}$ are sensitive to perturbations from emissions of polar stratospheric clouds (PSCs). This work presents results of implementing a firstorder screening for effects of PSCs using simple algorithms based on vertical gradients of the $\mathrm{O}_{3}$ mixing ratio. Their occurrences are compared with the co-located, retrieved temperatures and related to the temperature thresholds needed for saturation of $\mathrm{H}_{2} \mathrm{O}$ and/or $\mathrm{HNO}_{3}$ vapor onto PSC particles. Observed daily locations where the major PSC screening criteria are satisfied are validated against PSCs observed with the Stratospheric Aerosol Monitor (SAM) II experiment also on Nimbus 7. Remnants of emissions from PSCs are characterized for $\mathrm{O}_{3}$ and $\mathrm{HNO}_{3}$ following the screening. PSCs may also impart a warm bias in the co-located LIMS temperatures, but by no more than $1-2 \mathrm{~K}$ at the altitudes of where effects of PSCs are a maximum in the ozone; thus, no PSC screening was applied to the V6 temperatures. Minimum temperatures vary between 187 and $194 \mathrm{~K}$ and often occur 1 to $2 \mathrm{~km}$ above where PSC effects are first identified in the ozone (most often between about 21 and $28 \mathrm{hPa}$ ). Those temperature-pressure values are consistent with con-
\end{abstract}

ditions for the existence of nitric acid trihydrate (NAT) mixtures and to a lesser extent of super-cooled ternary solution (STS) droplets. A local, temporary uptake of $\mathrm{HNO}_{3}$ vapor of order $1-3 \mathrm{ppbv}$ is indicated during mid-January for the $550 \mathrm{~K}$ surface. Seven-month time series of the distributions of LIMS $\mathrm{O}_{3}$ and $\mathrm{HNO}_{3}$ are shown based on their gridded Level 3 data following the PSC screening. Zonal coefficients of both species are essentially free of effects from PSCs on the $550 \mathrm{~K}$ surface, based on their average values along PV contours and in terms of equivalent latitude. Remnants of PSCs are still present in $\mathrm{O}_{3}$ on the $450 \mathrm{~K}$ surface during midJanuary. It is judged that the LIMS Level 3 data are of good quality for analyzing the larger-scale, stratospheric chemistry and transport processes during the Arctic winter of 19781979.

\section{Introduction and objectives}

It is now well known that heterogeneous chemical reactions on surfaces of polar stratospheric clouds (PSCs) lead to an acceleration of the depletion of polar ozone in late winter and early spring (e.g., Solomon et al., 2015). Chemistry/climate models are showing that changes in the formation and persistence of PSC particles and of their related chemical effects are sensitive to changes in polar stratospheric temperatures, as well as to trends in ozone depleting substances (ODS). One current scientific need regarding stratospheric ozone is the "evaluation of the Antarctic ozone hole and Arctic win- 
ter/spring ozone depletion and the predicted changes in these phenomena, with a particular focus on temperatures in the polar stratosphere" (WMO, 2014). Therefore, it is important to characterize the occurrence frequency of PSCs, to compare their presence with the local temperature and chemical fields each winter/spring season, and to relate their current frequencies and effects with those of past decades.

The present study is an analysis for the effects of PSCs as determined for the Arctic winter of 1978-1979 from the Version 6 (V6) data set of the Limb Infrared Monitor of the Stratosphere (LIMS) experiment on Nimbus 7 (Gille and Russell, 1984). This report of the LIMS PSCs supplements the Stratospheric Aerosol Monitor (SAM) II observations of McCormick et al. (1982) and provides a baseline prior to significant losses of Arctic ozone. It will be shown that emissions from PSCs lead to perturbations in the LIMS-retrieved ozone and that they occur at temperatures that are slightly colder than the threshold or existence temperatures for nitric acid trihydrate $\left(T_{\mathrm{NAT}}\right)$. Those perturbations occur typically at altitudes 1 to $2 \mathrm{~km}$ below minimum temperatures $\left(T_{\min }\right)$ for the profiles. Criteria are described for the screening of the effects of the PSCs from the LIMS V6 species profiles. Daily surface maps are then generated from the screened data set to compare the geographic location of PSC effects identified from LIMS to the PSCs observed by SAM II and to determine the extent to which there are residual effects in V6 ozone, nitric acid, and temperature. Time series of sightings of the effects of PSCs are shown and interpreted according to their associated temperature and potential vorticity distributions.

LIMS provided daily, along-orbit samplings of the effects of PSCs and of their co-located temperatures in the Arctic stratosphere. Note that LIMS did not make measurements poleward of $65^{\circ} \mathrm{S}$ and did not observe the winter season of the southern hemisphere. An early analysis of the LIMS Version 5 (V5) Level 2 (or profile) data set was conducted for evidence of emissions from PSCs, and those initial results were reported at a NASA Workshop (Hamill and McMaster, 1984). Figure 1 reproduces a V5 ozone mixing ratio profile of 11 January from the Workshop report, and it shows a large, spurious excess of ozone centered near $50 \mathrm{hPa}$ that was attributed to effects of emissions from PSCs. The LIMS radiance profiles were re-processed in 2002 using Version 6 (V6) algorithms to obtain profiles of temperature, chemical species, and an additional quantity, geopotential height, as a function of pressure from about $65^{\circ} \mathrm{S}$ to $84^{\circ} \mathrm{N}$ latitude (Remsberg et al., 2004).

Spang et al. (2016) give a very good survey of the occurrences of PSCs in the Arctic (and Antarctic) winter stratosphere and over many winters. They provide excellent inferences about the likely PSC composition based on the spectral features in their satellite limb radiances and on the polarization characteristics of the PSC particles gained with colocated satellite lidar return signals. Spang et al. (2016) also provide information on the co-located environmental tem-

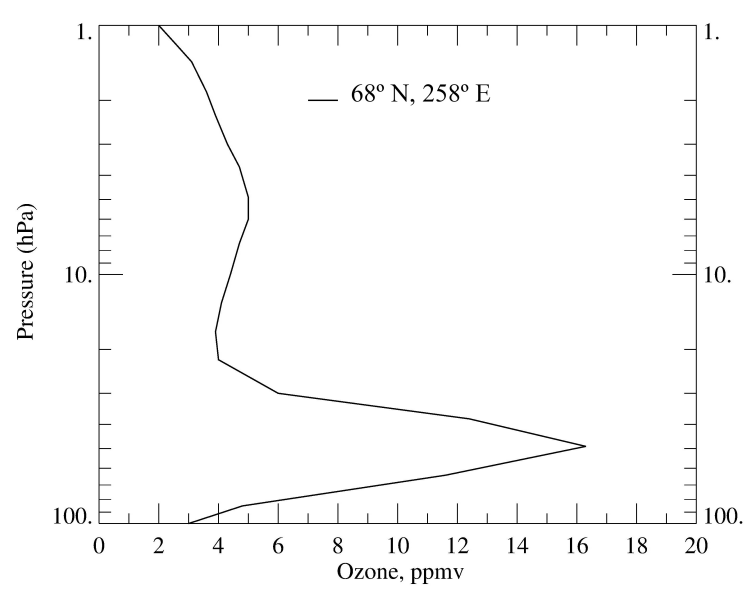

Figure 1. LIMS V5 ozone mixing ratio profile at $68^{\circ} \mathrm{N}, 258^{\circ} \mathrm{E}$ on 11 January 1979, showing effects of uncorrected emissions from PSCs below about the $20 \mathrm{hPa}$ level.

peratures. The LIMS V6 data yield complementary findings about the occurrences of PSCs from their effects in the retrieved V6 ozone profiles plus co-located V6 temperature distributions from the same satellite sensor, but for the much earlier period of 1978-1979. Estimates of the uptake of $\mathrm{HNO}_{3}$ vapor are given herein for that early period for the first time. Finally, we report that there are only minor and brief interferences from PSCs in the distributions of the Level $3 \mathrm{HNO}_{3}$, such that one can analyze for the relative contributions of chemistry vs. transport in their time series in the lower stratosphere.

The findings from LIMS V6 are organized as follows. Section 2 contains background information on the LIMS experiment, its earlier V5 data set, and improvements with V6. Section 3 includes a characterization of the mapped distributions of ozone, nitric acid, temperature, and geopotential height from V6. It is shown that there is a good relationship at $31.6 \mathrm{hPa}$ between the highest values of nitric acid vapor, lowest values of ozone, and lowest values of geopotential height (polar vortex region). Section 3 then describes criteria for screening the effects of significant emissions from PSCs using the V6 ozone and compares them to the effects in $\mathrm{HNO}_{3}$ and temperature. Section 4 explains that there can be "false positives" of effects from PSCs but that those instances occur mainly in early February 1979. Section 5 is a summary of the occurrences of Arctic PSCs and their associated temperatures for the winter of 1978-1979; the daily instances are in separate, archived files.

Section 6 compares the findings for V6 temperature, $\mathrm{HNO}_{3}$, and $\mathrm{O}_{3}$ with estimates of the composition and temperature thresholds from more recent measurements of PSCs and from thermodynamic equilibrium calculations for the uptake of $\mathrm{HNO}_{3}$ vapor onto PSC particles based on the work of Hansen and Mauersberger (1988) and Carslaw et al. (1995). It is shown that significant zonal wave- 1 forcings bring about 
rapid exchanges of $\mathrm{O}_{3}$ and $\mathrm{HNO}_{3}$ between middle and polar latitudes in early December and late January (e.g., Leovy et al., 1985). The mapped data and the time series analyses are examined for instances of uptake or loss of $\mathrm{HNO}_{3}$ vapor as well as instances of the advection of low values of $\mathrm{O}_{3}$ and $\mathrm{HNO}_{3}$ to the vortex from lower latitudes. Section 7 provides evidence for a local, temporary uptake of $\mathrm{HNO}_{3}$ vapor onto PSC particles, when temperatures are less than $194 \mathrm{~K}$. The findings of uptake from LIMS V6 are also compared with the more comprehensive determinations of Pitts et al. (2013). Section 8 also shows the evolution of $\mathrm{O}_{3}$ and $\mathrm{HNO}_{3}$ with respect to potential vorticity for the entire 71/4 months of the LIMS experiment. Those time series are based on the LIMS Level 3, zonal Fourier coefficients derived from the profile data, and it will be shown that they are essentially free of PSC effects on the $550 \mathrm{~K}$ potential temperature surface (near $31.6 \mathrm{hPa}$ ) but that there are some remaining perturbations in the ozone of mid-January on the $450 \mathrm{~K}$ surface (near $46.4 \mathrm{hPa}$ ). Both species show the combined effects of meridional transport and mixing during the winter months. Section 9 summarizes the primary findings of this study.

\section{Overview of the effects of clouds in the LIMS measurements}

This section reviews findings about PSCs from LIMS V5 and the changes adopted for identifying them in V6. LIMS obtained profiles of atmospheric limb radiance in six instrument channels, a wide $(\mathrm{W})$ and a narrow $(\mathrm{N})$ band channel for $\mathrm{CO}_{2}\left(\mathrm{CO}_{2} \mathrm{~W}\right.$ and $\left.\mathrm{CO}_{2} \mathrm{~N}\right)$ and one each for $\mathrm{O}_{3}, \mathrm{H} 2 \mathrm{O}, \mathrm{HNO}_{3}$, and $\mathrm{NO}_{2}$. The bandpass filters (in $\mathrm{cm}^{-1}$ ) for the channels are $\mathrm{CO}_{2} \mathrm{~W}$ (579-755), $\mathrm{CO}_{2} \mathrm{~N}$ (637-673), $\mathrm{O}_{3}$ (926-1141), $\mathrm{H}_{2} \mathrm{O}$ (1370-1560), $\mathrm{HNO}_{3}$ (844-917), and $\mathrm{NO}_{2}(1560-1630)$ in terms of their $5 \%$ relative response points. Temperature was retrieved based on the $\mathrm{CO}_{2} \mathrm{~W}$ channel radiances below about the $10 \mathrm{hPa}$ level. The channels for $\mathrm{H}_{2} \mathrm{O}$ and $\mathrm{NO}_{2}$ have an instantaneous field-of-view (IFOV) vertical width of $3.6 \mathrm{~km}$ at the horizon, while the other four channels have half that width or $1.8 \mathrm{~km}$ (see Gille and Russell, 1984; Remsberg et al., 1990 for more details about the LIMS instrument and the domain of its atmospheric measurements).

Radiances from the LIMS species channels are affected by emissions from cloud tops, and the retrieved LIMS mixing ratio profiles contain features due to them. None of the LIMS species channels have a bandwidth that is free of their target gases, such that one can attempt to characterize emissions from only the clouds and/or aerosols. For the sensing of PSC effects in the radiances about the best that one can do is to consider anomalies in profiles of the ratio of the water vapor radiance to the $\mathrm{CO}_{2} \mathrm{~W}$ radiance. But the IFOVs of the $\mathrm{H}_{2} \mathrm{O}$ and $\mathrm{CO}_{2} \mathrm{~W}$ channels are not compatible, which means that one cannot properly account for the corresponding radiances from temperature itself. Effects of emissions from clouds are delineated best with the narrow-IFOV, $\mathrm{O}_{3}$ and $\mathrm{HNO}_{3}$ channels. Yet, cloud occurrences are more pronounced in the retrieved $\mathrm{O}_{3}$ than in $\mathrm{HNO}_{3}$ because the relation between mixing ratio and radiance is non-linear for LIMS $\mathrm{O}_{3}$. Pressure levels of perturbations from cloud tops are included in a header line for every V6 profile, so that effects of cirrus clouds could be screened from them prior to the processing of the profiles with the LIMS Level 3 mapping algorithm (e.g., Remsberg et al., 1990).

Although the spectral effects of emissions from PSCs were not understood well in the 1970s, there are obvious effects from them in the LIMS retrieved ozone (Fig. 1) and in $\mathrm{H}_{2} \mathrm{O}$ (not shown). Since the ozone channel has a vertical IFOV width that is half that of the $\mathrm{H}_{2} \mathrm{O}$ channel, it is easier to obtain an accurate vertical location of the effects of PSCs from ozone. The archived profiles carry a pressure vs. altitude or $p(z)$ index of where the perturbing effects of PSCs are first noted in the ozone profiles. However, profile segments that are affected by those emissions were not screened out prior to their insertion into the V5 mapping algorithm; instead, their presence showed up clearly as "bull's-eye-like" features or as localized ozone maxima in preliminary maps of the daily parameters on pressure surfaces. Those occurrences are reported in Remsberg et al. (1986, their Tables 6 and 7 and Fig. 4). Then, the vertical segments that gave rise to them were removed using conservative latitude/longitude templates of the affected regions followed by a final mapping of the V5 profile data.

The same PSC templates were applied in the map analyses of the V5 temperatures, and those maps were also inspected for evidence of perturbing effects (Remsberg et al., 1986, their Appendix A). Independently, Austin et al. (1986) compared the V5 temperature profiles with those from the TIROS-N Stratospheric Sounding Unit (SSU) for the winter Arctic vortex region, and they found that the SSU $T$ was colder at $30 \mathrm{hPa}$ on average than that of V5, but not by much (SSU minus LIMS $T=-0.8 \pm 2.8 \mathrm{~K}$ ). They noted that the pressure modulation radiometry (PMR) measurement technique of the SSU sensor is essentially unaffected by interfering emissions from PSCs. Thus, Austin et al. (1986) concluded that the V5 temperature profiles were perturbed very little at $30 \mathrm{hPa}$ by radiances from the PSCs.

Austin et al. (1986) and Remsberg et al. (1986) reported that the locations of effects of PSCs in the V5 data agreed well with independent determinations of PSC extinction from the SAM II experiment, when their measurements overlapped spatially. Further, McCormick et al. (1982) reported moderate levels of extinction from SAM II PSCs at altitudes between 17 and $20 \mathrm{~km}$ and with co-located temperatures of 193 and $196 \mathrm{~K}$, according to gridded analyses provided to them by the NOAA Climate Prediction Center (CPC). They also reported that minimum temperatures from the CPC analyses ranged from 192 to $194 \mathrm{~K}$ and occurred at altitudes of 19 to $22 \mathrm{~km}$ or several kilometers above where PSC extinctions were at a maximum. Based on the foregoing realizations, it is likely that $T_{\min }$ from the LIMS profiles is within 
its estimated uncertainties and can be used to define the atmospheric environment for the existence of PSCs. Therefore, it was decided that no screening for PSC effects would be applied in the algorithm for the temperature profiles of V6. This approach means that the V6 temperature and associated geopotential height profiles are spaced continuously along the orbits and extend down to tops of clouds or near to or even below the tropopause, which is helpful for the assimilation of the temperatures into atmospheric models for studies of stratospheric transport.

Improvements that were implemented for V6 include a better registration for the LIMS radiances and the use of updated spectroscopic line parameters for retrievals of the species profiles. In addition, the retrievals for V6 were conducted for each profile pair at a spacing of $1.6^{\circ}$ of latitude (at the Equator) along orbits, instead of every $4^{\circ}$ as with V5. A screening for the effects of the PSC emissions was conducted for the V6 species profiles. Remnants of PSC effects are present in ozone and water vapor $\left(\mathrm{H}_{2} \mathrm{O}\right)$, but are much less apparent in nitric acid $\left(\mathrm{HNO}_{3}\right)$ vapor and nitrogen dioxide $\left(\mathrm{NO}_{2}\right)$. Thus, one can effectively look for any changes in $\mathrm{HNO}_{3}$ and $\mathrm{NO}_{2}$ adjacent to the PSCs because their fields have little to no contamination. Emissions from PSCs are minimal in the LIMS $15 \mu \mathrm{m} \mathrm{CO}_{2}$ radiances, and their effects are nearly absent in the V6 temperatures. More importantly, the V6 temperature and species profiles have a common effective vertical resolution of $3.7 \mathrm{~km}$, yielding co-located profile parameters that are compatible spatially. As a result, the LIMS V6 data set is judged to be of good quality and is part of the SPARC Data Initiative (e.g., Tegtmeier, et al., 2013).

Retrievals of V6 temperatures and associated species were obtained by using all successive, up/down scan profile pairs along their observed, orbital tangent-path locations and at 18 levels per decade of pressure, or at a spacing of about $0.88 \mathrm{~km}$. Thus, spurious perturbations in the retrieved ozone are recorded with better vertical and along-orbit sampling than was the case for the V5 data analyzed by Austin et al. (1986). A screening was performed and V6 species profile segments were removed, as follows. First, entire profiles were deleted whenever the ozone mixing ratio was greater than $20 \mathrm{ppmv}$ within the pressure range of 0.2 to $50 \mathrm{hPa}$. Those rare instances are attributed to perturbations in the motion of the instrument scan mirror that affected the subsequent registration of the measured radiance profiles. Then, a further screening for emissions from cirrus clouds was conducted based on instances of abrupt, spurious increases in the ozone mixing ratio in the region of the tropopause. That screening was conducted below the $45 \mathrm{hPa}$ level equatorward of $30^{\circ}$ latitude and below the $100 \mathrm{hPa}$ level poleward of that, as discussed in Remsberg et al. (2007).

\section{Detection and screening of effects of PSCs for LIMS V6}

\subsection{Meteorological context}

This section considers effects of PSCs in the V6 retrieved species and temperatures, presents the geographical evolution of remnants of PSCs following their first-order screening, and compares the location of those remnants with extinction observations from SAM II. As an example, Fig. 2 shows northern hemisphere polar plots of the V6 Level 3 ozone, geopotential height, temperature, and nitric acid vapor at $31.6 \mathrm{hPa}$ for 11 January, a day when ozone profiles in the region of the polar vortex are contaminated by PSCs. The Level 3 algorithm consists of zonal Fourier coefficients for the mean and wavenumbers 1-6 that are obtained with a sequential estimation technique and are available at every $2^{\circ}$ of latitude and at 6 levels per decade of pressure, or having a vertical spacing of about $2.7 \mathrm{~km}$ (Remsberg and Lingenfelser, 2010). The V6 mapping algorithm was applied separately to sequences of profiles along each latitude circle. Since only a few profiles were perturbed and screened from the input files of each day, the mapped ozone of Fig. 2 displays the medium and large-scale variations accurately based on a gridding of those daily zonal coefficients at a longitude resolution of $5.625^{\circ}$. The good continuity of the ozone fields with latitude in Fig. 2 is a separate measure of the precision of the orbital data. At this point it is stressed that the species profile segments that were screened of significant effects from PSCs are not part of the input ozone data for Fig. 2. Thus, the centroid of ozone at about $70^{\circ} \mathrm{N}, 270^{\circ} \mathrm{E}$ that exceeds 4 ppmv is the result of the mapping of residual effects of emissions from the PSCs that are still present in the Level 2 profiles. Locations of ozone profile segments for 11 January that were flagged and screened out are indicated by the white plus signs in the panels of Fig. 2. Thus, it is the neighbors of those flagged ozone profiles (and not the flagged profiles themselves) that contribute to the excess ozone features in Fig. 2.

McCormick et al. (1982, their Table 1 and Fig. 3) reported a moderate level of stratospheric aerosol extinction at $1.0 \mu \mathrm{m}$ wavelength and centered at $18 \mathrm{~km}$ on 11 January 1979. The solid red dot in Fig. 2 is the location of that SAM II observation or just north and west of Hudson Bay, Canada, at $67^{\circ} \mathrm{N}$, $257^{\circ} \mathrm{E}$; it is at the edge of the excess of V6 ozone, indicating that PSC extinctions to the north were likely larger that day than what SAM II observed. It is also noted that the region of elevated ozone is where the LIMS temperatures are coldest $(<196 \mathrm{~K})$ and near the center of the polar vortex, as defined by the LIMS geopotential height field.

\subsection{Screening criteria for PSCs in ozone}

The LIMS V6 Level 2 screening criteria are described as follows. The primary criterion is denoted by a parameter la- 

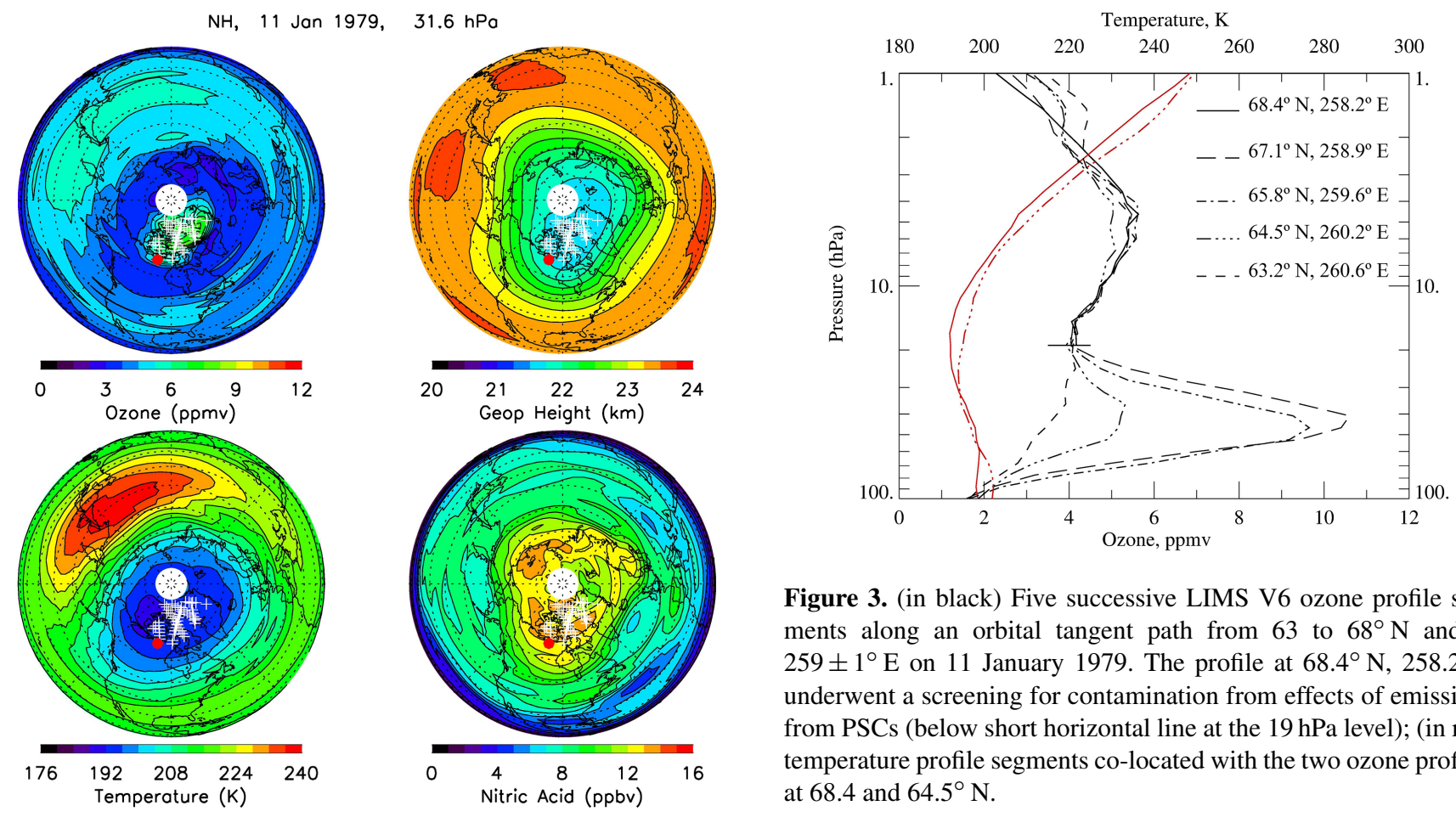

Figure 3. (in black) Five successive LIMS V6 ozone profile segments along an orbital tangent path from 63 to $68^{\circ} \mathrm{N}$ and at $259 \pm 1^{\circ} \mathrm{E}$ on 11 January 1979 . The profile at $68.4^{\circ} \mathrm{N}, 258.2^{\circ} \mathrm{E}$ underwent a screening for contamination from effects of emissions from PSCs (below short horizontal line at the $19 \mathrm{hPa}$ level); (in red) temperature profile segments co-located with the two ozone profiles at 68.4 and $64.5^{\circ} \mathrm{N}$.

Figure 2. Polar orthographic projections of Northern Hemisphere ozone (top left), geopotential height (gph, top right), temperature (bottom left), and nitric acid vapor (bottom right) for 11 January 1979 at $31.6 \mathrm{hPa}$; successive latitude circles are at every $10^{\circ}$. The Greenwich meridian extends horizontally to the right. Contour intervals are every $0.75 \mathrm{ppmv}$ for ozone, $0.25 \mathrm{~km}$ for gph, $4 \mathrm{~K}$ for temperature, and 1 ppbv for nitric acid vapor. White plus signs denote orbital profile segments that were screened out; red dot denotes location of SAM II PSC observation.

beled DIF in the daily files of ozone data points that were screened out. The DIF threshold was evaluated and then finally set as an absolute mixing ratio change of greater than 1.7 ppmv between two adjacent LIMS ozone profile points, spaced $0.88 \mathrm{~km}$ apart. As an example, Fig. 3 shows five successive V6 ozone profiles from 11 January along the orbital tangent path from 63.2 to $68.4^{\circ} \mathrm{N}$ and 258.2 to $260.6^{\circ} \mathrm{E}$. All five ozone profiles have similar values in the upper stratosphere, but their apparent mixing ratios differ markedly between 40 and $50 \mathrm{hPa}$. The $\mathrm{V} 6$ profile at $68.4^{\circ} \mathrm{N}$ is equivalent to the V5 ozone of Fig. 1, and the DIF criterion for the V6 profile was met at the $31.6 \mathrm{hPa}$ level. The level designated as free of PSC effects was set at four points above that, as denoted by the horizontal line at $19 \mathrm{hPa}$ in Fig. 3, to account for the finite FOV effects of the LIMS measurement and the vertical resolution of $3.7 \mathrm{~km}$ for its retrieved ozone. That profile and several adjacent ones poleward along the orbit were screened of effects from PSCs, as noted by the white plus symbols in Fig. 2. The DIF value is 2.2 ppmv for the V6 profile equivalent to that in Fig. 1, and it occurs at $31.6 \mathrm{hPa}$.

A secondary criterion is based on the absolute value of the ratio $f$ (labeled as a ratio or RTO parameter in those same data files) and defined as

$f=[q(n)-q(n-1)] / q(n-1)$.

Specifically, the RTO threshold was met when there was a change in the ozone mixing ratio $q$ with decreasing altitude between two adjacent profile points, $n-1$ and $n$, (spaced $0.88 \mathrm{~km}$ apart) such that $f$ in Eq. (1) was greater than 0.7 whenever $q(n-1)$ had a somewhat arbitrary value of greater than $0.5 \mathrm{ppmv}$. Note that the point index $n$ for a profile in the data file increases as altitude decreases, due to the nature of the "top-down" retrieval algorithm. As with DIF, the screening based on the RTO criterion begins four points above where the threshold is met. The RTO threshold is complementary to DIF and accounts for occurrences of anomalous vertical structure in ozone, where the ozone mixing ratio is small (but $>0.5 \mathrm{ppmv}$ ). Only two profiles met the RTO threshold on 11 January (near $82^{\circ} \mathrm{N}, 180^{\circ} \mathrm{E}$ ), and they occurred at the level of $88 \mathrm{hPa}$. The DIF threshold was also met for one of them at that level.

Another situation is shown by the long dashed profile for $67.1^{\circ} \mathrm{N}, 259^{\circ} \mathrm{E}$ in Fig. 3, where the ozone between 27.8 and $31.6 \mathrm{hPa}$ reaches an upper limit, DIF value of $1.6 \mathrm{ppmv}$, while the RTO value is only 0.23 ; the DIF and especially the RTO values are under the thresholds for perturbing effects from PSCs such that this profile survives the somewhat liberal screening criteria. Ozone profiles in Fig. 3 just equatorward of the PSC-screened profile are included in the surface maps of $\mathrm{O}_{3}$ and $\mathrm{HNO}_{3}$ shown in Fig. 2, even though 
they also contain residual effects of emissions from PSCs. The zonal mapping algorithm for a given latitude responds to the residual features of 11 January and also to any perturbations that may have occurred on the several days both prior to and following it. One final screening criterion was imposed based on whenever the retrieved ozone mixing ratio dropped below 0.2 ppmv. Such small values were assigned to the tangent layer as a consequence of a matching of the calculated forward radiances to the measured radiances, which is inherent in the onion-peeling retrieval method of LIMS. Those rare occurrences are considered as "false positives" for PSCs, and they are discussed in Sect. 4.

\subsection{Temperature profiles}

Initially, Crutzen and Arnold (1986) and Schlager and Arnold (1990) reported that the composition of PSC particles and their threshold or existence temperatures were more consistent with that of nitric acid tri-hydrate (NAT) than of water ice. Later, Knudsen (1996) concurred by showing that the temperatures from stratospheric analyses were warmer than the threshold temperatures for PSC particles composed of water ice, or $T_{\text {ICE}}$, which he calculated as being $186.4 \mathrm{~K}$ at $30 \mathrm{hPa}(\approx 22.6 \mathrm{~km})$ and $189.2 \mathrm{~K}$ at $50 \mathrm{hPa}(\approx 18.6 \mathrm{~km})$, according to an environmental water vapor mixing ratio of 5 ppmv. Those conditions were not met most times; coldest temperatures in the vicinity of PSCs were often a few degrees warmer than $T_{\text {ICE }}$ (see also McCormick et al., 1982; Hamill and McMaster, 1984; Austin et al., 1986). Knudsen (1996) also calculated threshold temperatures for NAT $\left(T_{\mathrm{NAT}}\right)$ of $192.9 \mathrm{~K}$ at $30 \mathrm{hPa}$ and of $195.5 \mathrm{~K}$ at $50 \mathrm{hPa}$, based on water vapor of 5 ppmv and a January LIMS nitric acid profile at $76^{\circ} \mathrm{N}$ having values of the order of $10 \mathrm{ppbv}$ at $30 \mathrm{hPa}$ and $7 \mathrm{ppbv}$ at $50 \mathrm{hPa}$. Occasionally, we found LIMS temperatures that remained cold at lower pressure-altitudes, too, as for the two instances on 11 January cited above where the RTO threshold was exceeded at $88 \mathrm{hPa}$. Temperatures for those profiles were $\sim 196 \mathrm{~K}$ from 53 to $88 \mathrm{hPa}$ and even colder $(\sim 193 \mathrm{~K})$ at $150 \mathrm{hPa}$.

Figure 3 also shows two co-located LIMS V6 temperature profiles for 64.5 and $68.4^{\circ} \mathrm{N}$, and they have minima of $193.9 \mathrm{~K}$ at $24.5 \mathrm{hPa}$ and $191.9 \mathrm{~K}$ at $16.7 \mathrm{hPa}$, respectively, or near to $T_{\mathrm{NAT}}$. Temperatures at $46 \mathrm{hPa}$ are warmer by 3 and $6 \mathrm{~K}$, respectively, or where the associated, perturbed ozone mixing ratios are largest. Note that the temperature profile at $64.5^{\circ} \mathrm{N}$ has its minimum at $24.5 \mathrm{hPa}$ and then rises smoothly toward larger pressures and that the temperatures at $68.4^{\circ} \mathrm{N}$ are slightly warmer than the ones at $64.5^{\circ} \mathrm{N}$ from about 35 to $60 \mathrm{hPa}$. This finding indicates that the retrieved temperatures at $68.4^{\circ} \mathrm{N}$ are perturbed slightly by emissions from PSCs at the pressures levels, where their perturbing effects on ozone are largest.

The effects of PSC perturbations in ozone are enhanced at the lower level of $46 \mathrm{hPa}$, as shown in Fig. 4. Locations of PSC contaminated profiles for 11 January in Fig. 2 have not
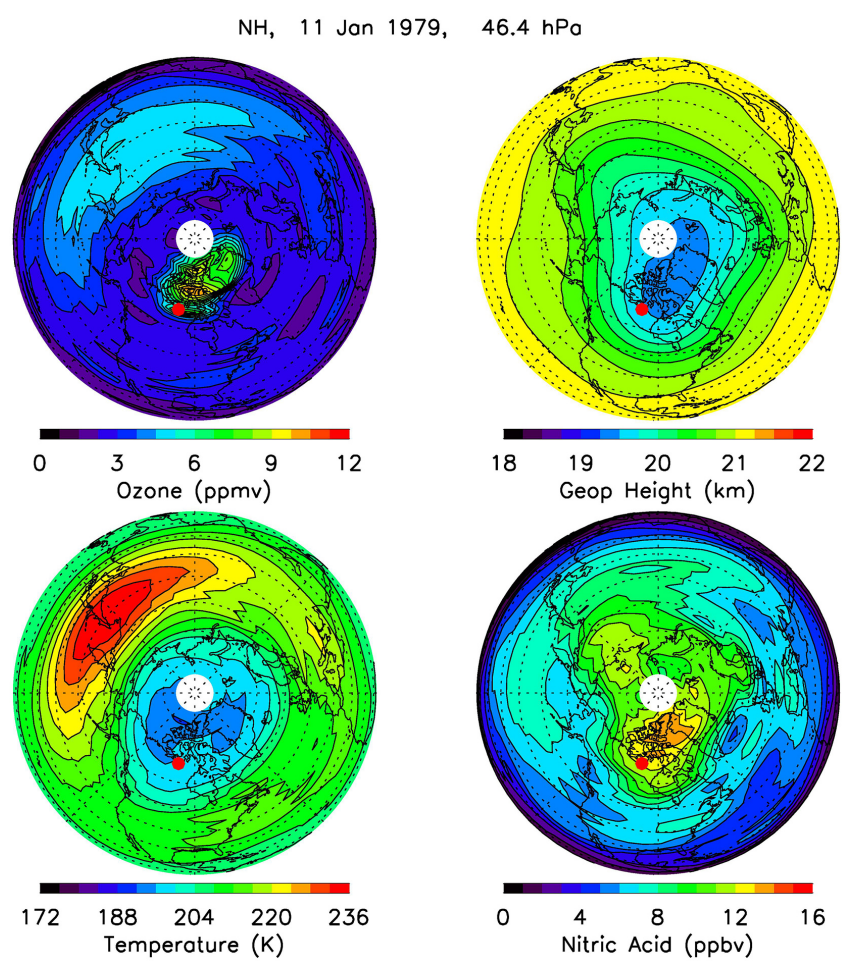

Figure 4. As in Fig. 2 for 11 January, but for the $46.4 \mathrm{hPa}$ level; the white plus signs have been removed to give better clarity for the underlying fields.

been plotted onto Fig. 4, although the SAM II sighting has been retained. The ozone panel of Fig. 4 shows maximum ozone remnants due to unscreened PSCs at about $75^{\circ} \mathrm{N}$, $270^{\circ} \mathrm{E}$. The corresponding panel for temperature shows values in the same location that are slightly warm $(>196 \mathrm{~K})$ compared with the colder values $(<196 \mathrm{~K})$ at adjacent longitudes, even though both locations are within the polar vortex (see panel for geopotential height). That region of slightly elevated temperatures is very likely the result of not screening for effects of PSCs from the V6 temperature profiles.

At this point it should be clear that there are significant residual effects of PSCs in ozone at $31.6 \mathrm{hPa}$ (Fig. 2), but that they are essentially absent in the temperature. Thus, it is possible to know where PSCs are located based on the ozone field, but also to be confident that there is little impact at $31.6 \mathrm{hPa}$ for the co-located temperature fields and no impact on geopotential height for calculations of the associated species transport. It is presumed that the LIMS temperatures are within their estimated accuracies at and above where the effects of PSCs are small in the co-located ozone. Tighter criteria can screen out more instances of PSC contamination from the species but may also remove some profile segments having vertical structures due to real, transport-induced effects. In particular, a few instances of an overly tight screening have been found based on the RTO criterion at pressure levels from 52.7 to $100 \mathrm{hPa}$, as indicated by co-located tem- 
peratures that are much too warm for the existence of PSC particles.

\subsection{Nitric acid}

The LIMS-retrieved $\mathrm{O}_{3}$ and $\mathrm{H}_{2} \mathrm{O}$ have non-linear sensitivities to radiance or temperature biases (Remsberg et al., 2004). Distributions of LIMS $\mathrm{NO}_{2}$ are affected too, primarily because of the need to correct its radiances for interfering effects from the perturbed $\mathrm{H}_{2} \mathrm{O}$. However, $\mathrm{HNO}_{3}$ is affected much less as shown in its corresponding panels of Figs. 2 and 4 because the relationship between the observed $\mathrm{HNO}_{3}$ radiance and retrieved mixing ratio is nearly linear. In support of that finding, simulation studies show that a temperature bias error of $1 \mathrm{~K}$ has only a small, $3 \%$ effect on the retrieval of $\mathrm{HNO}_{3}$ between 10 to $50 \mathrm{hPa}$ (Remsberg et al., 2010, their Table 1). In addition, there are no clear anti-correlations between the distributions of temperature and nitric acid in Figs. 2 and 4; for example, relatively high values of $\mathrm{HNO}_{3}$ are found in both the cold vortex region near the pole and toward the much warmer Aleutian sector. This finding of a small anti-correlation between temperature and $\mathrm{HNO}_{3}$ is a consequence of the weak chemical reactivity of gas phase $\mathrm{HNO}_{3}$ in polar night (Brasseur and Solomon, 2005).

To what degree are there PSC remnants in the $\mathrm{V} 6 \mathrm{HNO}_{3}$ ? As examples, it was shown in Figs. 2 and 4 that there are remnants of PSCs from 260 to $360^{\circ} \mathrm{E}$ in ozone at 31.6 and $46.4 \mathrm{hPa}$ on 11 January and perhaps a slight excess in the nitric acid field in the same region. Figure 5 shows the V6 $\mathrm{HNO}_{3}$ profiles for 11 January that are co-located with the screened ozone profile and its adjacent ones of Fig. 3. Note that the maximum value of nitric acid for the unscreened $\mathrm{HNO}_{3}$ profile in Fig. 5 is about $13 \mathrm{ppbv}$ from 30 to $50 \mathrm{hPa}$ or essentially not much different from that at about $75^{\circ} \mathrm{N}$, $140^{\circ} \mathrm{E}$ in Fig. 2, where no effects of PSCs are indicated. It is also apparent from Fig. 2 that $\mathrm{HNO}_{3}$ has a smaller value of $10 \mathrm{ppbv}$ near $80^{\circ} \mathrm{N}, 0^{\circ} \mathrm{E}$ but near to the PSCs above northern Greenland. The corresponding temperature profile at $67.1^{\circ} \mathrm{N}, 258.9^{\circ} \mathrm{E}$ in Fig. 5 has a minimum value of $192.1 \mathrm{~K}$, which is cold enough for the uptake of $\mathrm{HNO}_{3}$ vapor onto NAT particles but not onto droplets of sulfuric acid and water to become a super-cooled, ternary solution (STS) of all three species; $T_{\mathrm{STS}} \sim 189 \mathrm{~K}$ at $30 \mathrm{hPa}$ (Pitts et al., 2013; Peter and Grooss, 2012).

McCormick et al. (1982) found PSCs from 18 to 22 January 1979, and they reported co-located temperatures that were very cold. SAM II PSC extinction values for 18, 19, and 22 January 1979 are 1 order of magnitude greater than on 11 January. Accordingly, Fig. 5 also shows a LIMS nitric acid profile for 19 January adjacent to one that was screened out along the same orbit and located very near to the profile of excessive PSC extinction found at $67.8^{\circ} \mathrm{N}, 43^{\circ} \mathrm{E}$ with SAM II. The $\mathrm{V} 6 \mathrm{HNO}_{3}$ profile has a maximum value of $17 \mathrm{ppbv}$ at about $25 \mathrm{hPa}$ or an excess of perhaps 4 ppbv compared with the more nominal profile of 11 January. Thus, the $\mathrm{HNO}_{3}$ re-

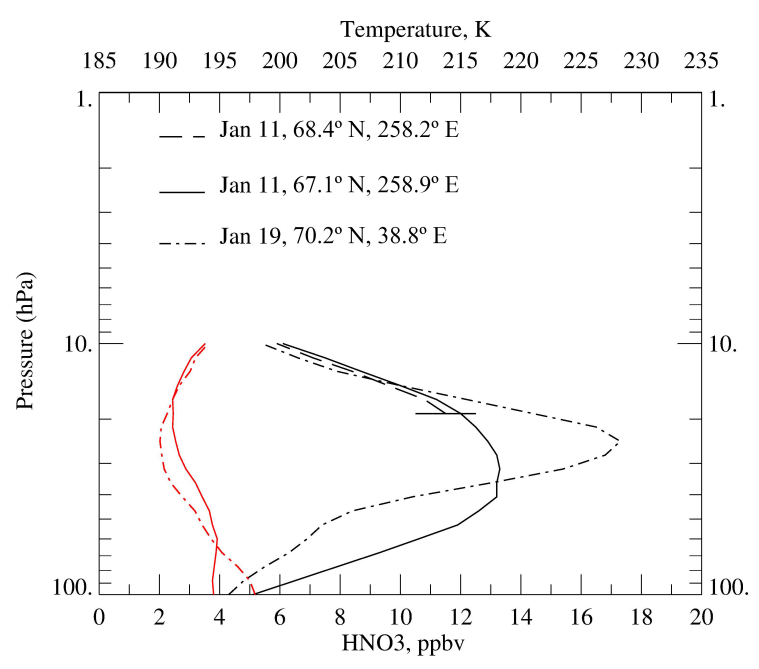

Figure 5. Profiles of LIMS V6 nitric acid vapor (in black) and two co-located profiles of temperature (in red) for 11 and 19 January. Horizontal line at $19 \mathrm{hPa}$ marks the cutoff level for valid nitric acid on 11 January and at $68.4^{\circ} \mathrm{N}, 258.2^{\circ} \mathrm{E}$.

sponse to those much larger PSC extinction values is definitely elevated, but not nearly to the extent of the response in ozone. The co-located LIMS temperature profile for 19 January is also shown in Fig. 5, and it has a minimum value of $190.1 \mathrm{~K}$ at $25 \mathrm{hPa}$.

\section{Anomalous indications of effects of PSCs from V6}

SAM II observed maximum extinctions from PSCs at about $68^{\circ} \mathrm{N}, 30^{\circ} \mathrm{E}$ and near $22 \mathrm{~km}$ on 18 and 19 January and then much smaller values on 20 and 21 January (see Table 1 in McCormick et al., 1982). Large extinctions were measured again on 22 January but shifted to the west or at $311^{\circ}$ E. Figure 6 shows the ozone panel for 22 January and the SAM II observation location (the solid red dot) over Greenland. It is in a region of cold temperatures $(192 \mathrm{~K}$ ) and at the western edge of a residual feature near $0^{\circ} \mathrm{E}$ in the LIMS ozone. The Aleutian anticyclone intensified by this date and moved the vortex off the pole. Figure 6 also shows the locations of profile segments that were screened out of the ozone along the 0,90 , and $125^{\circ} \mathrm{E}$ meridians. In particular, the LIMS ozone profile segments at $125^{\circ} \mathrm{E}$ (white plus marks in Fig. 6) are located in a relatively warm region $(\sim 215$ to $220 \mathrm{~K})$ and are far above the temperature threshold for PSC formation.

The DIF and RTO ozone thresholds were met 52 and 6 instances, respectively, during 18-22 January. However, there were also 15 instances when the retrieved ozone dropped below $0.2 \mathrm{ppmv}$ and where the retrieved temperatures were often of the order of $200 \mathrm{~K}$ or higher (between 14 and $46 \mathrm{hPa}$ ). Those instances are considered further with the aid of Fig. 7, which shows V6 ozone and temperature from four profiles along an orbit from 118 to $128^{\circ} \mathrm{E}$ on 22 January. Three of 
Table 1. Occurrences of signatures of PSCs in the LIMS V6 ozone profiles of 1978/79. Central latitude and longitude locations of the PSCs and their extent ( \pm in degrees) are given for each day that they are found along with the average pressure level (in hPa) at which those perturbing effects are absent, or $\mathrm{PSC}_{\text {top }}$, for pressure levels between 14.7 and $46.4 \mathrm{hPa}$. The number of profiles where the DIF threshold was met is indicated to the right in the column for $\mathrm{PSC}_{\text {top }}$, and the number of "false positives" is given to the right of the slash symbol (e.g," three scans met the DIF criterion on 2 February and one of those was a "false positive" denoted as 3/1). The minimum temperature in the set of profiles and its pressure level is given in the next two columns. Calculated relative humidity (RH in \%) with respect to ice is in the last column, based on an ambient water vapor mixing ratio of $6.0 \mathrm{ppmv}$.

\begin{tabular}{|c|c|c|c|c|c|c|}
\hline Date & $\mathrm{Lat}^{\circ} \mathrm{N}$ & Long $^{\circ} \mathrm{E}$ & $\begin{array}{l}\text { PSC (top), } \\
\text { hPa; \# DIF }\end{array}$ & $\begin{array}{r}\text { Minimum } \\
\text { temp, } \mathrm{K}\end{array}$ & $\begin{array}{r}P(\mathrm{hPa}) \text { at } \\
T \text { min }\end{array}$ & $\begin{array}{r}\text { RH with respect to } \\
\text { Ice }(\%)\end{array}$ \\
\hline 29 Nov & $74 \pm 2$ & $0 \pm 2$ & 22,3 & 188.6 & 24.5 & 58 \\
\hline $30 \mathrm{Nov}$ & $72 \pm 5$ & $23 \pm 6$ & 22,13 & 188.8 & 21.5 & 49 \\
\hline $1 \mathrm{Dec}$ & $71 \pm 3$ & $45 \pm 5$ & 32,9 & 190.2 & 31.6 & 57 \\
\hline $2 \mathrm{Dec}$ & $73 \pm 3$ & $12 \pm 28$ & 22,5 & 190.4 & 21.5 & 38 \\
\hline $3 \mathrm{Dec}$ & 71 & 8 & 22,1 & 191.5 & 16.7 & 24 \\
\hline $27 \mathrm{Dec}$ & 76 & 4 & 28,1 & 192.1 & 19.0 & 25 \\
\hline $28 \mathrm{Dec}$ & $76 \pm 3$ & $356 \pm 20$ & 22,8 & 190.5 & 21.5 & 37 \\
\hline $30 \mathrm{Dec}$ & $76 \pm 4$ & $352 \pm 14$ & 25,8 & 190.7 & 21.5 & 36 \\
\hline $1 \mathrm{Jan}$ & $70 \pm 4$ & $359 \pm 17$ & 22,9 & 191.0 & 27.8 & 44 \\
\hline 2 Jan & $73 \pm 5$ & $332 \pm 42$ & 25,31 & 190.2 & 24.5 & 44 \\
\hline 3 Jan & $70 \pm 6$ & $340 \pm 50$ & $25,36 / 1$ & 190.5 & 24.5 & 42 \\
\hline 4 Jan & $67 \pm 6$ & $348 \pm 36$ & 25,19 & 191.4 & 24.5 & 36 \\
\hline 5 Jan & $73 \pm 3$ & $22 \pm 3$ & 32,7 & 191.8 & 31.6 & 44 \\
\hline 8 Jan & $79 \pm 4$ & $333 \pm 43$ & 22,27 & 189.5 & 24.5 & 50 \\
\hline 9 Jan & $76 \pm 8$ & $335 \pm 55$ & 28,78 & 189.3 & 24.5 & 52 \\
\hline $10 \mathrm{Jan}$ & $77 \pm 7$ & $312 \pm 68$ & 28,78 & 189.9 & 24.5 & 47 \\
\hline 11 Jan & $76 \pm 6$ & $289 \pm 41$ & 28,52 & 189.8 & 21.5 & 42 \\
\hline 13 Jan & $75 \pm 9$ & $273 \pm 31$ & 28,26 & 190.2 & 21.5 & 39 \\
\hline 14 Jan & $74 \pm 8$ & $270 \pm 9$ & 32,11 & 189.9 & 21.5 & 41 \\
\hline 15 Jan & $77 \pm 2$ & $276 \pm 19$ & 36,5 & 191.0 & 21.5 & 34 \\
\hline 16 Jan & $79 \pm 2$ & $283 \pm 19$ & 32,3 & 191.4 & 21.5 & 32 \\
\hline 17 Jan & $71 \pm 5$ & $7 \pm 17$ & 17,11 & 185.7 & 24.5 & 97 \\
\hline 18 Jan & $70 \pm 7$ & $31 \pm 16$ & 17,21 & 186.3 & 27.8 & 99 \\
\hline 19 Jan & $65 \pm 8$ & $45 \pm 13$ & 22,15 & 188.1 & 21.5 & 56 \\
\hline $20 \mathrm{Jan}$ & $57 \pm 4$ & $50 \pm 1$ & 15,6 & 187.5 & 14.7 & 42 \\
\hline 21 Jan & $55 \pm 3$ & $91 \pm 21$ & $32,3 / 2$ & 191.7 & 31.6 & 44 \\
\hline 22 Jan & $65 \pm 5$ & $47 \pm 47$ & $17,7 / 5$ & 190.1 & 21.5 & 40 \\
\hline 23 Jan & $65 \pm 2$ & $359 \pm 14$ & $28,5 / 1$ & 192.0 & 27.8 & 37 \\
\hline $2 \mathrm{Feb}$ & 74 & 52 & $28,3 / 1$ & 196.5 & 40.8 & 26 \\
\hline $3 \mathrm{Feb}$ & 76 & 78 & $19,6 / 5$ & 197.2 & 35.9 & 21 \\
\hline $4 \mathrm{Feb}$ & 73 & $70 \pm 1$ & $27,23 / 21$ & 196.4 & 46.4 & 30 \\
\hline $5 \mathrm{Feb}$ & $81 \pm 2$ & $75 \& 125$ & $27,29 / 27$ & 196.9 & 40.8 & 25 \\
\hline $6 \mathrm{Feb}$ & $82 \pm 1$ & $80 \& 112$ & $27,38 / 36$ & 195.8 & 46.4 & 34 \\
\hline $7 \mathrm{Feb}$ & 78 & 70 & $32,18 / 17$ & 197.7 & 46.4 & 25 \\
\hline 9 Feb & $76 \pm 1$ & $92 \pm 2$ & $36,4 / 2$ & 196.4 & 40.8 & 27 \\
\hline
\end{tabular}

the four profiles met the ozone screening criteria, while one did not. All four profiles exhibit considerable vertical structure. The RTO threshold was met at $60 \mathrm{hPa}$ for the profile at $73.0^{\circ} \mathrm{N}, 126.7^{\circ} \mathrm{E}$ and was also very nearly met at $41 \mathrm{hPa}$ for the profile at $74.3^{\circ} \mathrm{N}, 128.3^{\circ} \mathrm{E}$, even though both profiles were far from the DIF threshold. In addition, the retrieved ozone profile at $61.4^{\circ} \mathrm{N}, 119.5^{\circ} \mathrm{E}$ has a mixing ratio of $5.5 \mathrm{ppmv}$ at $19 \mathrm{hPa}$, but then drops below $0.2 \mathrm{ppmv}$ by $31.6 \mathrm{hPa}$; screening begins four points higher or at the $19 \mathrm{hPa}$ level, as denoted by the horizontal bar. That ozone profile has a co-located, temperature of $264.2 \mathrm{~K}$ at $10 \mathrm{hPa}$, but then decreases rapidly to $211.8^{\circ} \mathrm{K}$ at $31.6 \mathrm{hPa}$ (Fig. 7-solid red curve). Since V6 temperatures have a finite vertical resolution, it is likely that the true atmospheric temperature profile had a vertical gradient even larger. Thus, these V6 temperatures may be biased warm by several degrees at pressure levels from 19 to $31.6 \mathrm{hPa}$, such that the ozone retrieval algorithm assigns little to no ozone to the tangent layer.

More significantly, the LIMS observations for the orbit along the $125^{\circ} \mathrm{E}$ meridian on 22 January were made viewing 

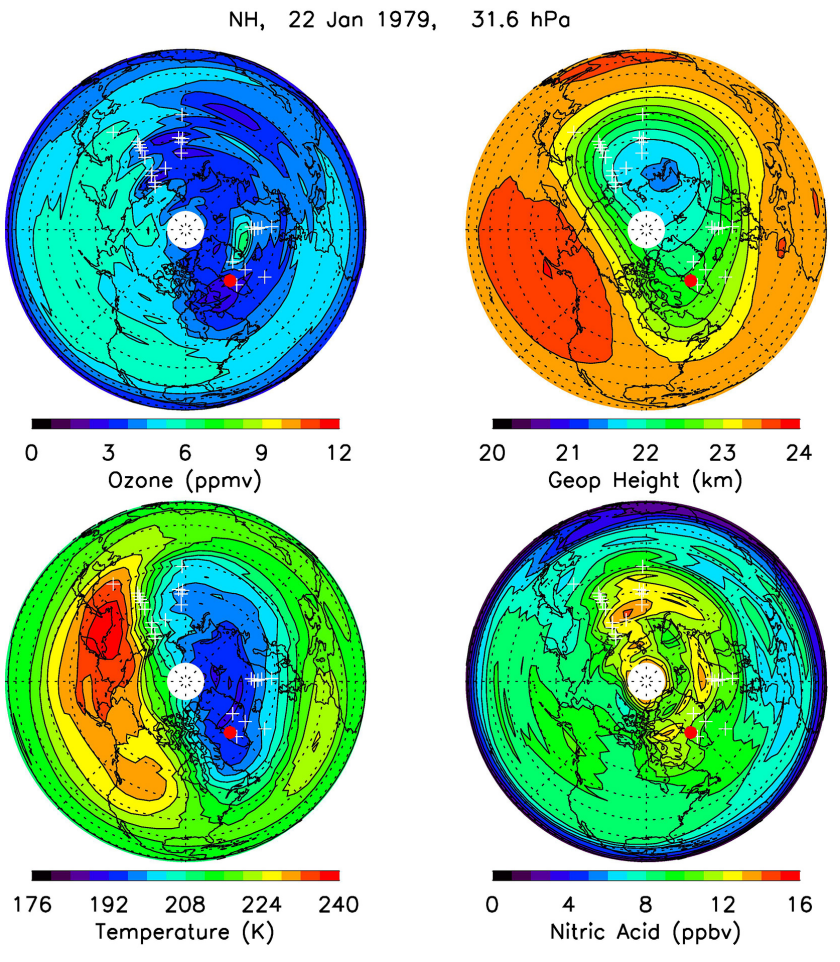

Figure 6. As in Fig. 2, but for 22 January 1979.

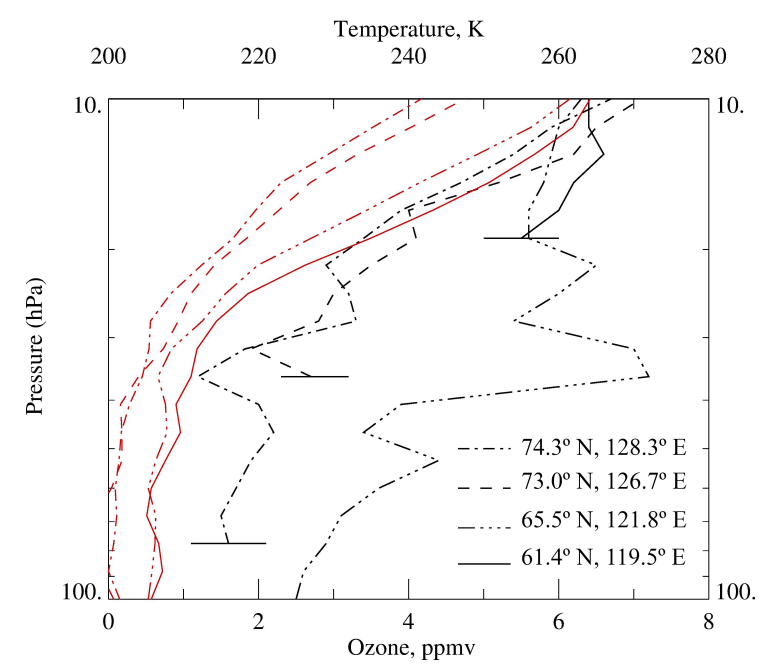

Figure 7. (in black) Four ozone profile segments along an orbital tangent path from 61.4 to $74.3^{\circ} \mathrm{N}$ and 119.5 to $128.3^{\circ} \mathrm{E}$ on $22 \mathrm{Jan}-$ uary 1979 and where short horizontal lines denote the lower altitude limit of good data; (in red) temperature profiles co-located with the ozone.

toward the east and in the direction of the strong horizontal temperature gradient (see Fig. 6). In other words, the lineof-sight geometry for those ascending orbital observations were toward much higher temperatures (see Remsberg et al. (1986), their Fig. 31, to determine the LIMS viewing geometry). Although the V6 algorithm accounts, to first order,

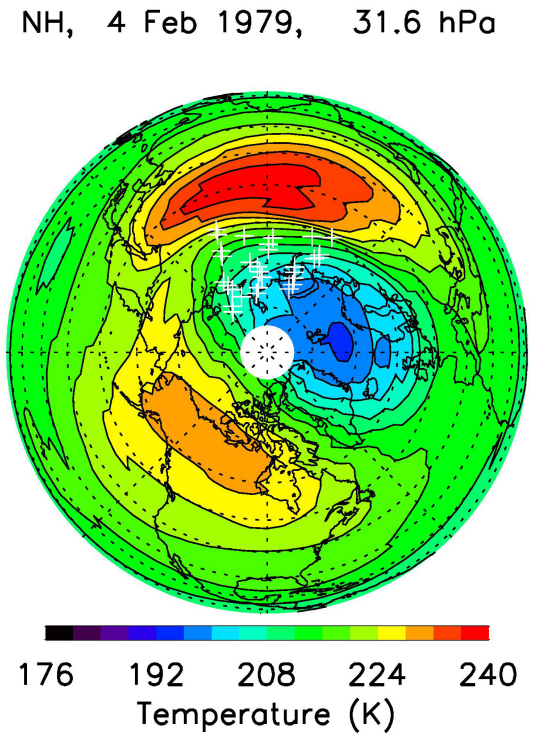

Figure 8. V6 temperatures at $31.6 \mathrm{hPa}$ and the locations of spurious PSC effects or "false positives" (white plus signs) for 4 February 1979.

for line-of-sight temperature gradients, the calculated LIMS radiances for the nominally, $300 \mathrm{~km}$ long, tangent path are based on a mean Planck blackbody function that is weighted necessarily by the higher temperatures at the far side of the tangent layer. Again, little to no ozone is required at the next lower tangent layer, in order to achieve a match between the calculated and observed radiances for the retrieval of ozone. The several profiles that were screened out along 118 to $126^{\circ} \mathrm{E}$ are "false positives" for PSCs; their ozone mixing ratios dropped below $0.2 \mathrm{ppmv}$ in a region of strong temperature gradients.

Figure 8 shows a number of "false positives" on the plot of temperature for 4 February, or at a time when a largeamplitude, wave-1 forcing had moved the vortex off the pole. Note that scans screened according to the DIF and/or RTO criteria are not located where the temperature is coldest, but instead where the horizontal temperature gradient is large. In addition, in the middle stratosphere the warmest temperatures are further poleward (not shown), such that vertical temperature gradients are also large from 7 to $31.6 \mathrm{hPa}$ in that region. Because retrieved ozone is sensitive to small biases in temperature, the co-located V6 ozone profiles exhibit anomalously large vertical gradients that often meet the PSC criteria. While this circumstance leads to false indications of PSCs, their ozone mixing ratios are spurious, too. The screening removes them, and they are also not part of the V6 Level 3 product. 


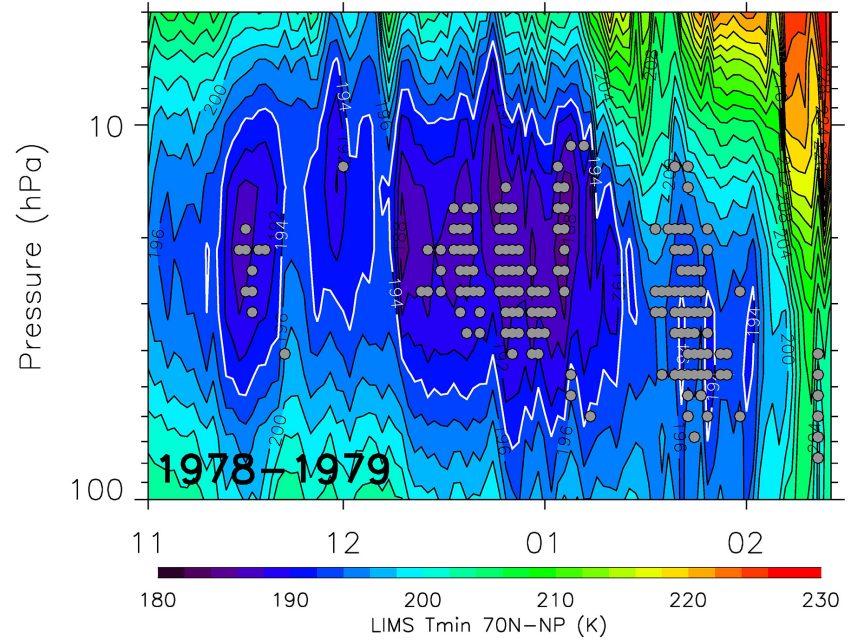

Figure 9. Daily time series of minimum V6 temperatures vs. pressure for the latitude zone of $70^{\circ} \mathrm{N}$ to the pole, plus locations of tops of PSCs (gray circles). Contour increment is $2 \mathrm{~K}$ and the white contour is $194 \mathrm{~K}$. The abscissa is from 15 November through 28 February.

\section{Occurrences of the effects of PSCs in regions of minimum temperatures}

Figure 9 is a time series of the daily occurrences of PSCs between $70^{\circ} \mathrm{N}$ and the pole, based on when the DIF and/or RTO criteria were met (gray circles), and of temperature for 15 November through the end of February. Note that often there were multiple scans on a given day that had the signature of PSC effects in ozone and their thresholds occurred for a range of pressure levels (between about 15 to $45 \mathrm{hPa}$ ). Those occurrences are related to the daily minimum temperatures for the same latitude band and also as a function of the pressure level. The white contour denotes $194 \mathrm{~K}$, and one can see that the effects of PSCs occurred at temperatures just below $192 \mathrm{~K}$, at least in early December and through January. The same threshold criteria were met at warmer temperatures ( $\sim 196 \mathrm{~K}$ or greater) in early February, or when most all of the "false positives" occurred.

Table 1 is a summary of the daily occurrences of PSC effects, as indicated by the DIF criterion, for the region poleward of $45^{\circ} \mathrm{N}$ and for the pressure range of 46.4 to 14.7 hPa. Pressure levels where ozone is first considered free of PSC effects, or $\mathrm{PSC}_{\text {top }}$, are listed along with their latitude and longitude locations designated in the Level 2 files "cloud_flags_data_psc" within the archival directory "Data_Screening". Typically, several successive ozone profiles are affected along a given orbit, so average locations and $\mathrm{PSC}_{\text {top }}$ values were obtained from them for Table 1 . Those daily occurrences have been compared with and are found to be similar to those for V5 in Austin et al. (1986, their Table 1). PSC features are found in the V6 ozone from 29 November to 3 December 1978, from 27 Decem- ber 1978 through 5 January 1979, from 8 January through 23 January 1979, and much less frequently in early February. In general, PSC effects from V6 are found over somewhat smaller geographical areas than from V5, due in part to the fact that the PSC effects of V6 are located more precisely. In addition, the V6 results are based on less conservative screening criteria, instead of being based on an inspection of anomalies in the preliminary, daily mapped ozone fields on pressure surfaces as for V5. Table 1 contains the daily averaged, upper-level pressures $\left(\mathrm{PSC}_{\mathrm{top}}\right)$, above where perturbations from PSCs are essentially absent in ozone. For example, the horizontal line on the ozone profile of Fig. 3 for 11 January denotes that location as $19 \mathrm{hPa}$. The designation, $\mathrm{PSC}_{\text {top }}$, is analogous to the parameter cloud top height (CTH), reported for PSCs by Spang et al. $(2001,2005)$ from the CRISTA-2 and the MIPAS data sets, respectively. Instances where the DIF criterion gave a "false positive" are also provided in that same column of Table 1.

LIMS V6 contains up to 3600 up/down profile pairs for each full day of operations. The LIMS DIF criterion (>1.7 ppmv) is satisfied in 502 profile pairs across 100 separate orbital segments and between 46.4 and $14.7 \mathrm{hPa}$ through the end of January. Those occurrences represent only $0.22 \%$ of all profile pairs for that period. The overall instances of DIF values are 252 (1.7 to $2.0 \mathrm{ppmv}$ ), 121 (2.0 to 2.3 ), 70 (2.3 to 2.6), 32 (2.6 to 2.9), 20 (2.9 to 3.2), and 7 (>3.2 ppmv). By comparison, the RTO criterion ( $>0.7$ ) is met only 20 times, exclusive of DIF, and for the much shorter time of 19 through 31 January. Instances for RTO are 7 (0.7 to 1.0), 5 (1.0 to 1.3), 5 (1.3 to 1.6$)$, and 3 (>1.6).

According to Fig. 9 and Table 1, PSCs developed in late November/early December, dissipated by 4 December, and then reformed by late December between 67 and $80^{\circ} \mathrm{N}$ and 336 to $50^{\circ} \mathrm{E}$, which is also the region of the cold polar vortex centered near the Greenwich meridian at that time. PSC $_{\text {top }}$ values are located between 30 and $21 \mathrm{hPa}$, but most often near $21 \mathrm{hPa}$. From 2 to 9 January the region of PSCs expanded and their average top-altitude descended slightly to the $24 \mathrm{hPa}$ level. Then, the vortex and the region of PSCs underwent a westward rotation to near $270^{\circ} \mathrm{E}$ (northern Canada) by 11 January. Ozone on that day was screened out within the region of $76 \pm 6^{\circ} \mathrm{N}, 289 \pm 41^{\circ}$ E. However, Fig. 3 shows that there was residual contamination from PSCs in several of the adjacent V6 ozone profiles. Thus, ozone remnants are found near where the effects of PSCs are identified, e.g., as in the ozone panels of Figs. 2 and 4.

Figure 9 and Table 1 show that PSC $_{\text {top }}$ moved downward from 9 to 15 January or between 28 and $36 \mathrm{hPa}$. On 17 and 18 January new PSCs developed at a higher level $(17 \mathrm{hPa})$ over northern Scandinavia or near $0^{\circ} \mathrm{E}$. The major stratospheric sudden warming (SSW) of late January brought much warmer air to the polar region and led to the dissipa-

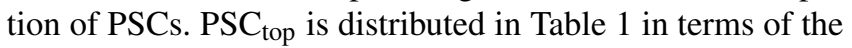
number of orbits for its sightings at a given pressure value according to occurrences through January: 4 at $14.7 \mathrm{hPa}, 3$ 
at $16.7 \mathrm{hPa}, 7$ at $19.0 \mathrm{hPa}, 33$ at $21.5 \mathrm{hPa}, 6$ at $24.5 \mathrm{hPa}, 33$ at $27.8 \mathrm{hPa}, 9$ at $31.6 \mathrm{hPa}, 4$ at $35.9 \mathrm{hPa}$, and 1 at $40.8 \mathrm{hPa}$. Most daily $\mathrm{PSC}_{\text {top }}$ occurrences are at $21.5 \mathrm{hPa}$ (33 sightings) and at $27.8 \mathrm{hPa}$ (33 sightings) with many fewer instances at the intervening level of $24.5 \mathrm{hPa}$ (6 sightings).

Table 1 also contains daily average calculations of relative humidity (RH in \%) with respect to ice (List, 1951) in the vicinity of $\mathrm{PSC}_{\text {top }}$, based on a nominal water vapor mixing ratio of $6 \mathrm{ppmv}$ and for the $T_{\min }$ values occurring in the pressure range of 14.7 and $46.4 \mathrm{hPa}$. $T_{\min }$ is found at the same pressure level as $\mathrm{PSC}_{\text {top }}$ for a subset of 11 of the 31 days. Those two parameters occurred at the same level most often for $21.5 \mathrm{hPa}(4), 24.5 \mathrm{hPa}(3)$, and $31.6 \mathrm{hPa}$ (3). Average $T_{\min }$ for those instances is $189.5 \mathrm{~K}$ at $21.5 \mathrm{hPa}, 190.7 \mathrm{~K}$ at $24.5 \mathrm{hPa}$, and $191.2 \mathrm{~K}$ at $31.6 \mathrm{hPa}$, and the average $\mathrm{RH}$ is $45 \%$ for this set of 10 cases. Thus, the V6 results imply that PSCs formed very close to the altitude of the minimum temperature and exist at values 2 to $3 \mathrm{~K}$ above $T_{\mathrm{ICE}}, 2$ to $3 \mathrm{~K}$ below $T_{\mathrm{NAT}}$, but near to $T_{\mathrm{STS}}$. Those findings are generally consistent with the observed levels for the maximum departure of temperature below that of $T_{\mathrm{NAT}}$ in Pitts et al. (2011, their Fig. 17a). In addition, Fig. 9 shows that the PSCs were found within a $10 \mathrm{~km}$ deep layer. Temperatures barely dropped to $192 \mathrm{~K}$ at $50 \mathrm{hPa}$ in Fig. 9 and very seldom extended to $188 \mathrm{~K}$ at $30 \mathrm{hPa}$, indicating that a hygroscopic, liquid NAT mixture rather than STS is the most likely component of the PSCs, according to Pitts et al. (2013, their Fig. 2). The calculated RH (ice) in Table 1 approaches $100 \%$ for a brief time on 17 and 18 January just north of Scandinavia and where temperature dropped to near $185 \mathrm{~K}$. Those conditions indicate the presence of PSC particles composed of STS or even ice, possibly due to effects of ascent and adiabatic cooling following an orographic or synoptic-scale forcing (e.g., Grewe and Dameris, 1997; Carslaw et al., 1998).

While the retrieved LIMS V6 temperatures may be biased a degree or so too warm at pressure levels having significant emissions from PSCs, they would not be biased similarly at and above $\mathrm{PSC}_{\text {top }}$, at least away from regions having large temperature gradients. Most researchers have used colocated, re-analysis temperatures from nadir-viewing sensors (like the Stratospheric Sounding Unit, SSU) or from data assimilation models for their interpretations of the formation and maintenance of satellite-observed PSCs (e.g., Höpfner et al., 2006; Spang et al., 2005; Pitts et al., 2011). Pawson et al. (1999) considered layer-mean temperatures derived from geopotential thicknesses from SSU radiance profiles and compared them with $\mathrm{T}$ analyses of the Freie Universitaät Berlin (FUB) from their network of radiosonde (RAOB) data. They found SSU-RAOB differences that were small and of the order of 1 to $2 \mathrm{~K}$, although they also found that the sign of those differences depended on the vertical gradient of the temperature profile. Typically, the SSU values were a bit higher than the FUB analyses at $50 \mathrm{hPa}$ but lower at 20 to $30 \mathrm{hPa}$ or near $\mathrm{PSC}_{\text {top. }}$. They attributed that variation with pressure to the relatively low vertical resolution of the SSU measurements ( $10 \mathrm{~km}$ at best) and to a difficulty with allocating any changes in the SSU radiances to equivalent variations of the layer-averaged temperature, at least at the altitude of $T_{\text {min. }}$. As noted earlier, LIMS radiances for the retrieval of temperature below the $10 \mathrm{hPa}$ level are based on its $\mathrm{CO}_{2} \mathrm{~W}$ channel measurements, and they are affected very little by added emissions from a PSC. Thus, one clear advantage of LIMS V6 vs. SSU is that LIMS viewed the altitude region of $T_{\min }$ more directly; the retrieved $\mathrm{V} 6$ temperatures have a vertical resolution of $3.7 \mathrm{~km}$.

\section{PSCs from LIMS and SAM II and their co-located temperature, $\mathrm{HNO}_{3}$, and $\mathrm{O}_{3}$}

Figure 10 (left) is a record of the evolution from 20 November 1978 through 30 January 1979 in terms of the minimum temperature vs. longitude at the $550 \mathrm{~K}$ level (near $31.6 \mathrm{hPa}$ ) for the latitude region of 65 to $70^{\circ} \mathrm{N}$ or the domain where SAM II made observations. PSC sightings from the V6 ozone are over plotted as gray circles on this diagram along with the $194 \mathrm{~K}$ contour (in the manner of Hovmöller, 1949). In most instances locations of effects of PSCs are within the $194 \mathrm{~K}$ contour, which is the nominal threshold temperature at this level for the existence of PSCs composed of NAT particles. Locations of observations of PSCs from SAM II are over plotted as black circles, and the LIMS results agree well with them. This finding is an important verification of the locations of PSCs based on the LIMS ozone. The LIMS PSCs of 22 and 23 January at 100 to $120^{\circ}$ E represent instances, when the RTO threshold was met and when the temperature was well above $194 \mathrm{~K}$. These several cases are false indications of PSCs. Figure 10 (right) shows the corresponding mean gas phase $\mathrm{HNO}_{3}$ at $550 \mathrm{~K}$ for the same latitude domain; the white contour is 10 ppbv. PSCs occurred in the polar vortex where temperatures (at left) were cold but also where $\mathrm{HNO}_{3}$ had its maximum values. This finding is typical of their anti-correlation in the polar winter vortex, where $\mathrm{HNO}_{3}$ is the reservoir for $\mathrm{NO}_{x}$ during the polar night. However, the retrieved, gas phase $\mathrm{V} 6 \mathrm{HNO}_{3}$ may also be contaminated (high) slightly at locations of PSCs due to their excess emissions.

Figure 11 is analogous to Fig. 10, but for the domain of $70^{\circ} \mathrm{N}$ to the pole and for the period of 25 November through 20 January. The three panels of Fig. 11 are Hovmöller diagrams at $550 \mathrm{~K}$ of (left) minimum temperature, (middle) minimum $\mathrm{HNO}_{3}$, and (right) maximum ozone. Minima and maxima are the min or max values for each longitude as observed between $70^{\circ} \mathrm{N}$ and the pole. The left panel has the LIMS PSCs over plotted on it, and the $194 \mathrm{~K}$ contour is shown as a proxy for temperatures that support NAT PSCs. The $10 \mathrm{ppbv} \mathrm{HNO}_{3}$ contour is shown in white for the middle panel. Maximum ozone in the right panel serves to highlight any remnants of PSCs, as otherwise ozone is always low inside the winter vortex. Ozone remnants show up clearly over 


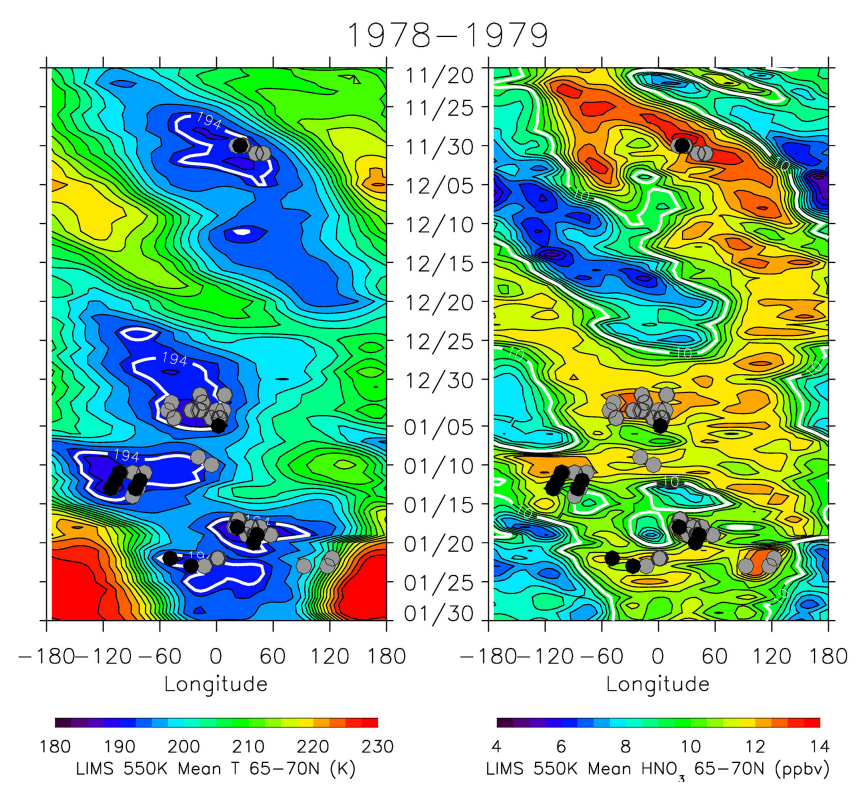

Figure 10. Hovmöller diagram (time vs. longitude) of the effects of PSCs from LIMS V6 (gray circles) and from SAM II (black circles) for 20 November 1978 to 30 January 1979. (left) Locations of PSC sightings are over plotted on fields of daily mean temperature between 65 and $70^{\circ} \mathrm{N}$; contour interval is $2.5 \mathrm{~K}$ and the white contour is $194 \mathrm{~K}$. (right) The fields are of daily mean $\mathrm{HNO}_{3}$; contour interval is $0.5 \mathrm{ppbv}$ and white contour is $10 \mathrm{ppbv}$.

the Greenwich Meridian in late November/early December and in late December, and then north of Greenland in middle January. Those relatively high max ozone patterns are indicative of the locations of LIMS PSCs.

Figure 11 shows the influence of the Canadian warming of early December on the position of the polar vortex, the reformation of a cold vortex and its embedded PSCs from late December through middle January, and then the development of the warm Aleutian anticyclone and its encroachment toward the vortex during late January. The PSC of 6 December near $-100^{\circ}$ longitude is a definite outlier in that it occurs in a region where the local temperature is near $215 \mathrm{~K}$. Even though retrieved ozone drops to zero at $46.4 \mathrm{hPa}$ for that profile, the DIF criterion is met first at the next higher level $(40.8 \mathrm{hPa})$. There is also a large temperature gradient along the tangent layer at that location, so that PSC feature is considered as a "false positive" like those on 22 and 23 January in Fig. 10. One can also see in the middle panel the large values of $\mathrm{HNO}_{3}(12 \mathrm{ppbv})$ of late autumn, the poleward advection of much lower values to the pole in early December, the re-establishment of high values by late December, and then followed by $\mathrm{HNO}_{3}$ values of less than $10 \mathrm{ppbv}$ that indicate a loss or uptake of 1-3 ppbv of gas phase $\mathrm{HNO}_{3}$ just after the occurrence of the large numbers of PSCs of 8-10 January.

LIMS observed PSC emissions from 29 November through 4 December and then more consistently from 27 December through January. SAM II also made measurements

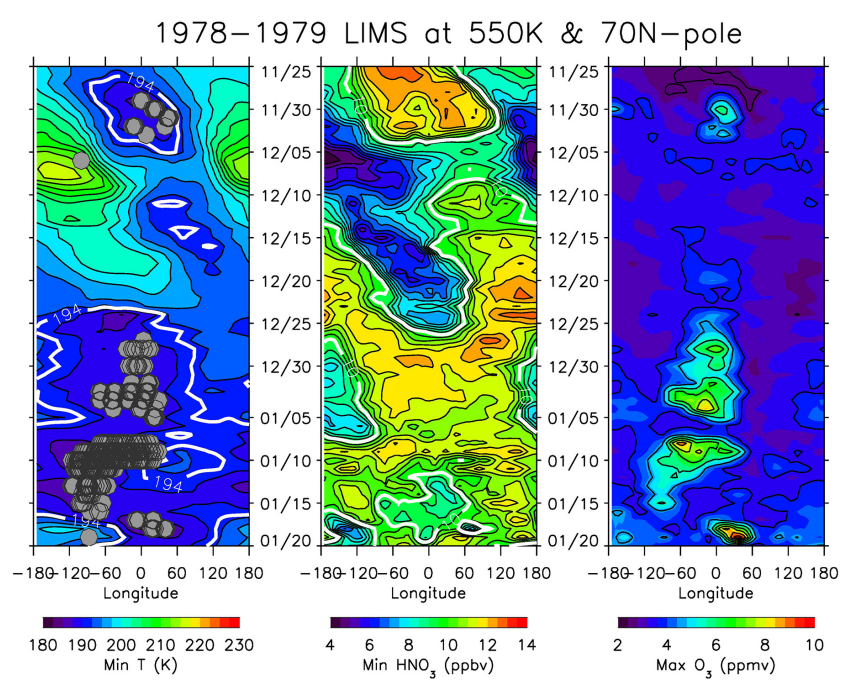

Figure 11. As in Fig. 10, but for the latitude domain of $70^{\circ} \mathrm{N}$ to the pole and from 25 November through 20 January; (left) fields of daily minimum temperature, (middle) daily minimum $\mathrm{HNO}_{3}$, and (right) daily maximum ozone.

of enhanced extinction on 30 November and 5 January at the low latitude boundary of where LIMS found largest effects in its ozone. The vortex was split on 6 December, following from a so-called "Canadian warming" event. There was a poleward advection of much lower values of $\mathrm{HNO}_{3}$ from low latitudes to the pole across the Alaska sector, following that. Those low values show up clearly in Figs. 10 and 11 during the middle of December. PSC effects occurred much more frequently from 2 to 6 January at about 70 to $80^{\circ} \mathrm{N}$ and between -60 and $+30^{\circ}$ longitude and remained nearly stationary. Temperatures in that region were definitely cold enough $(<192 \mathrm{~K})$ for the existence of PSCs, and it is very likely that there was some uptake of $\mathrm{HNO}_{3}$ vapor onto the particles at that time. Still, because that excess emission from the PSCs was also within the center of the vortex it is difficult to distinguish an uptake (decrease) of any gas phase $\mathrm{HNO}_{3}$ at the same locations.

From 8-11 January the character of the vortex underwent a change, such that one can begin to look for a loss of $\mathrm{HNO}_{3}$ away from PSCs. In particular, on 14 January there are PSC remnants in ozone at about $75^{\circ} \mathrm{N}, 270^{\circ} \mathrm{E}$, having $\mathrm{PSC}_{\text {top }}$ at $33.4 \mathrm{hPa}$ and a $T_{\min }$ of $189.8 \mathrm{~K}$ at $21.5 \mathrm{hPa}$ (Table 1). Figure 11 shows that $\mathrm{HNO}_{3}$ has a maximum of $12 \mathrm{ppbv}$ over Siberia $\left(120^{\circ} \mathrm{E}\right)$ on 14 January and smaller values $(\sim 9 \mathrm{ppbv})$ at the center of the vortex $\left(0\right.$ to $\left.60^{\circ} \mathrm{E}\right)$ or also where the colocated ozone is only 3 ppmv. Although a relative minimum of $\mathrm{HNO}_{3}$ of $9 \mathrm{ppbv}$ is equivalent to its values at the middle latitudes, the 3 ppmv ozone is an isolated, absolute minimum for this potential temperature level and is representative of minimum ozone values within the polar vortex. For this reason it is unlikely that nitric acid of 9 ppbv is a result of advection from lower latitudes, but instead represents qualita- 


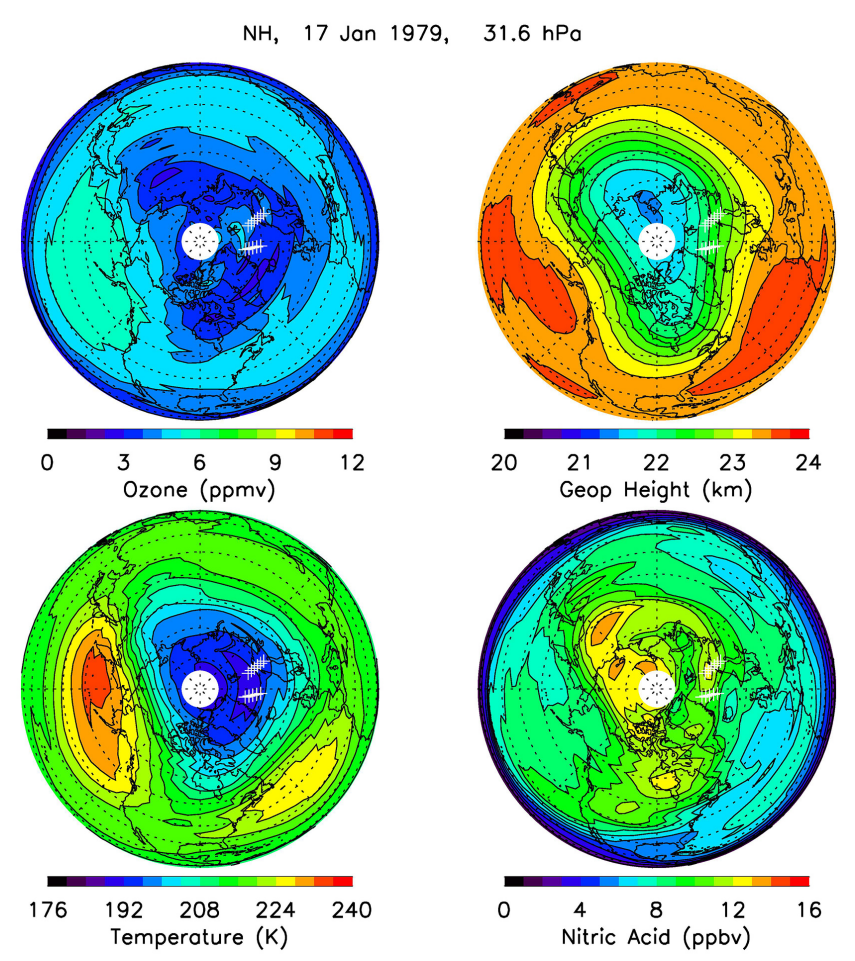

Figure 12. As in Fig. 2, but for 17 January.

tive evidence of a loss or an earlier uptake of nitric acid vapor onto PSC particles directly upwind of and in a region where $T$ is $\sim 192 \mathrm{~K}$.

From 14 to 17 January the Aleutian anticyclone expanded and distorted the vortex, such that the polar low filled at $290^{\circ} \mathrm{E}$ but deepened at $110^{\circ} \mathrm{E}$. The region of coldest temperatures shifted to the east. The data of Table 1 indicates that the PSCs of 16 January at $79^{\circ} \mathrm{N}, 283^{\circ} \mathrm{E}$ and at $31.6 \mathrm{hPa}$ were dissipated by 17 January, while new PSCs appeared at $71^{\circ} \mathrm{N}, 7^{\circ} \mathrm{E}$ and at a pressure level of $15.7 \mathrm{hPa}$. Figure 12 is the 4-panel plot for 17 January, and it characterizes the polar stratosphere during a period of a large number of PSCs (see Fig. 11). In fact, the largest PSC extinction value measured by SAM II occurred on 18 January at $67.7^{\circ} \mathrm{N}, 22^{\circ} \mathrm{E}$. The polar vortex and its low values of ozone in Fig. 12 are nearly centered over the pole. White plus symbols indicate the V6 PSCs that were screened out for 17 January, and they occurred in the region of coldest temperatures $(\sim 188$ to $192 \mathrm{~K}$ ). Remnants of PSCs are apparent in the panel for ozone just poleward of that. The cyclonic circulation about the vortex transported air parcels eastward from near $290^{\circ} \mathrm{E}$, across the Greenwich meridian, and into the region of coldest temperatures, or just where PSC remnants are indicated by the elevated ozone values. The co-located $\mathrm{HNO}_{3}$ appears as an isolated region of relatively low values ( $9 \mathrm{ppbv})$ near to the PSCs and indicates a region of de-nitrification of the air flowing across the PSC particles.
To summarize, the only clear evidence for an uptake of gas phase $\mathrm{HNO}_{3}$ from Fig. 11 is found on 6-8 January and from 10-20 January, and where PSCs are not contaminating the retrieved profiles. Estimates of the uptake vary from 1-3 ppbv. Any greater local losses of $\mathrm{HNO}_{3}$ are obscured by the finite tangent-path averaging inherent in the LIMS measurements. PSCs over a range of longitudes for periods of 3 to 4 days in mid-January are also consistent with the time needed for an uptake of $\mathrm{HNO}_{3}$ into NAT mixtures (Pitts et al., 2013, their Fig. 5). The temporary uptake of $\mathrm{HNO}_{3}$ is considered a bit further in the next section.

\section{Temperature threshold for the uptake of $\mathrm{HNO}_{3}$ vapor}

Figure 13 is a scatterplot of minimum values of $\mathrm{HNO}_{3}$ vs. minimum temperatures at $550 \mathrm{~K}$ and for the domain of $70^{\circ} \mathrm{N}$ to the pole based on the data from 1-20 January of the Hovmöller diagrams in Fig. 11 (left and middle panels). A temperature threshold of $194 \mathrm{~K}$ is marked by the vertical dashed line. The points of Fig. 13 are partitioned and colored in terms of their separate, successive 5-day time periods. Coldest temperatures occurred during 6-10 and 11-15 January, and the air became warmer over part of the spatial domain by 16-20 January. Points colored gray have associated ozone values of 6 ppmv or greater as shown also in the right panel of Fig. 11, and they indicate instances when the $\mathrm{HNO}_{3}$ points are likely contaminated by residual emissions from PSCs. Most of those gray points occur at the relatively cold temperatures of 190 to $192 \mathrm{~K}$ and have $\mathrm{HNO}_{3}$ values between 10.5 and $12.5 \mathrm{ppbv}$. There are also a few gray points from 16-20 January having temperatures between 187 and $188 \mathrm{~K}$ and $\mathrm{HNO}_{3}$ values of about 9.5 to 10.5 ppbv. Still, there is little indication of an uptake of $\mathrm{HNO}_{3}$ vapor from this scatterplot.

The points from each 5-day time period of Fig. 13 are grouped now according to how many instances are within each $2 \mathrm{~K}$ temperature bin and at a bin spacing of $0.25 \mathrm{ppbv}$ in $\mathrm{HNO}_{3}$. Those distributions or "clouds of points" are contoured in Fig. 14 for each of the four time periods. Points carrying ozone values $>6$ ppmv are not counted in the totals for Fig. 14, and bins containing less than 2 points are not contoured. The centroid for the "cloud of points" shows up clearly. That location is at about $11.7 \mathrm{ppbv}$ and $193 \mathrm{~K}$ for $1-$ 5 January, 11.5 ppbv and $192 \mathrm{~K}$ for 6-10 January, $10.9 \mathrm{ppbv}$ and $191 \mathrm{~K}$ for $11-15$ January, and $11.1 \mathrm{ppbv}$ and $192 \mathrm{~K}$ for 16-20 January. Yet, it is also clear from Fig. 14 that the separate clouds of points have become elongated toward lower values of the $\mathrm{HNO}_{3}$ from 1-20 January. This finding is our best indication of $\mathrm{HNO}_{3}$ uptake (by 1 to 3 ppbv) or of a denitrification process at those cold temperatures. The somewhat anomalous, secondary maximum of points centered at 9 ppbv and $194 \mathrm{~K}$ for $1-5$ January is the result of air of those 


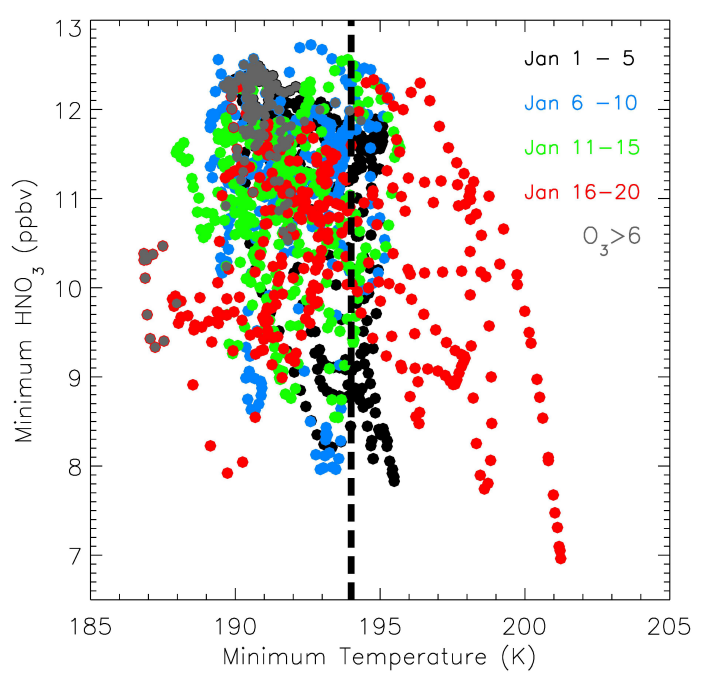

Figure 13. Scatterplot of minimum values of $\mathrm{HNO}_{3}$ vs. minimum values of temperature for the domain of $70^{\circ} \mathrm{N}$ to the pole at $550 \mathrm{~K}$ for the period of 1-20 January (from Fig. 11); the vertical dashed line denotes $194 \mathrm{~K}$. Colors correspond to data values in each of the separate 5-day periods. Points having corresponding values of ozone $>6$ ppmv are shown in gray.

values that was advected the previous week from middle to high latitudes.

Our estimates of uptake of $\mathrm{HNO}_{3}$ by PSCs are consistent with findings in the literature from others (Höpfner et al., 2006; Arnone et al., 2012; Pitts et al., 2013). Such depletion of gas phase $\mathrm{HNO}_{3}$ has been shown more clearly with satellite measurements from the Sub Millimeter Radiometer (SMR) and the Microwave Limb Sounder (MLS) (Khosrawi et al., 2011). Still, it is helpful to be able to infer a depletion of the $\mathrm{HNO}_{3}$ vapor and also to know about the presence and composition of any co-located PSCs. To that end, Hoepfner et al. (1998) found that they could identify PSCs and that the infrared emissions from them amounted to a perturbation of only 2 to $3 \%$ in co-located, stratospheric column measurements of $\mathrm{HNO}_{3}$ vapor. The findings in Fig. 5 show that the effects of PSCs are also small in the $\mathrm{HNO}_{3}$ from LIMS V6.

Pitts et al. (2013) reported on their analyses of observations of Arctic PSCs, as obtained with the CALIOP (CloudAerosol Lidar with Orthogonal Polarization) satellite instrument. Pitts et al. (Fig. 2, 2013) also compared those results with box model simulations of the relevant gas-toparticle processes for the uptake of $\mathrm{HNO}_{3}$ vapor, based on the work of Carslaw et al. (1995) for STS and that of Hanson and Mauersberger (1988) for NAT. Yet, Pitts et al. (2013) found that uptake of $\mathrm{HNO}_{3}$ vapor onto STS particles is only efficient, when the environmental temperature is close to $T_{\text {ICE. According to their model, environmental temperatures }}$ must be below $189 \mathrm{~K}$ for that to occur at $30 \mathrm{hPa}$. The minimum LIMS temperatures in Table 1 indicate that this STS threshold was achieved only on 19 and 20 January. Pitts et

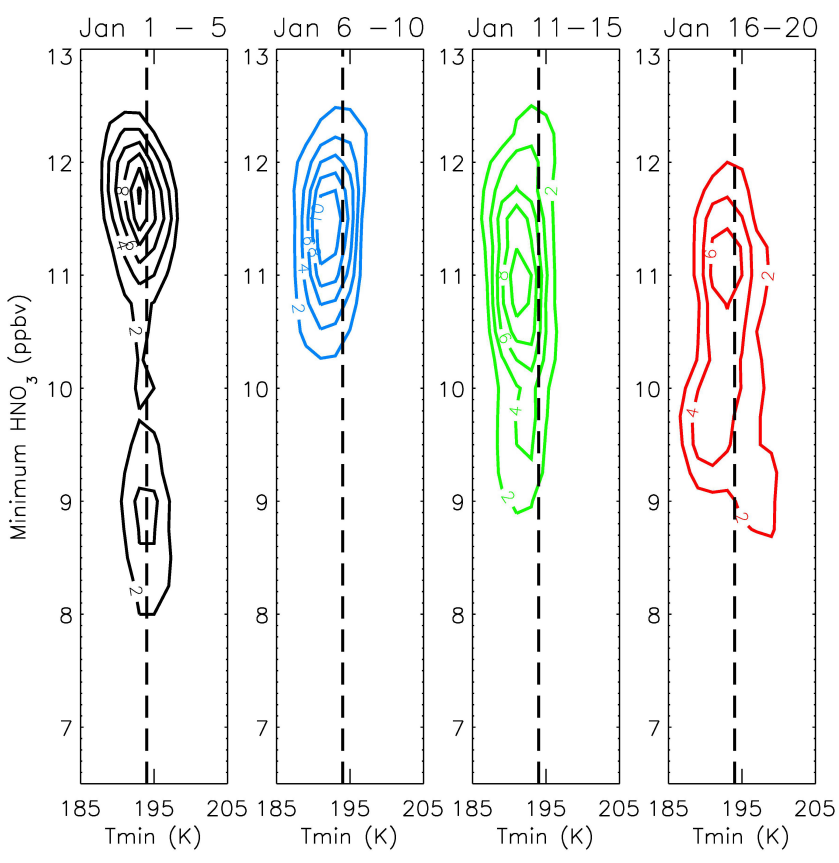

Figure 14. Contour plots of the frequency distributions of points from each of the 5-day periods in Fig. 13. Points from each distribution are binned according to intervals of $2 \mathrm{~K}$ and $0.25 \mathrm{ppbv}$ $\mathrm{HNO}_{3}$, and their cumulative numbers are contoured at a spacing of 2. Dashed vertical line is for $194 \mathrm{~K}$.

al. (2013) also found that an uptake of several ppbv of gas phase $\mathrm{HNO}_{3}$ can occur onto NAT particles, if the temperature remains below $193 \mathrm{~K}$ for the longer time of 2 to 3 days. Those conditions were met from 5 to 11 January 1979 (Table 1). NAT particles can also exist at $50 \mathrm{hPa}$, if temperatures dip below 195 K. However, Fig. 5 shows that environmental temperatures barely met that threshold and on only one day, 19 January, making any additional uptake unlikely at that pressure level.

Solomon et al. (2015) presented several model scenarios for the efficient uptake of $\mathrm{HNO}_{3}$ vapor and the growth of STS droplets but only when temperatures are below $192 \mathrm{~K}$. Their scenarios also required that there be significant supersaturation for the $\mathrm{HNO}_{3}$ vapor with respect to solid NAT particles or at temperatures below about $192 \mathrm{~K}$. Based on those assumptions, they achieved time series of model ozone loss for February and March that agreed well with observed polar ozone changes for the abnormally cold Arctic winter of 2011. By comparison, LIMS temperatures of $192 \mathrm{~K}$ or colder did not persist past 24 January, and there is no clear evidence for a corresponding heterogeneous loss of ozone during the winter of 1978-1979. 


\section{Seasonal evolution of potential vorticity, $\mathrm{HNO}_{3}$ and $\mathrm{O}_{3}$}

The previous sections demonstrate that it is important to be aware of the presence of PSC effects in both individual LIMS profiles and in localized regions of the mapped LIMS products. In this section it will be shown that the effects of the remnants of PSCs cover very little area of the northern hemisphere during the winter of 1978-79. First, Fig. 15 is a plot of the dynamical tracer, potential vorticity, on the isentropic surface of $550 \mathrm{~K}$ (or the PV at about $31.6 \mathrm{hPa}$ and $22 \mathrm{~km}$ ) for 17 January.

$\mathrm{PV}=(f+\zeta) / \sigma$,

where $f=2 \Omega \sin \varphi$ is the local vertical component of the planetary vorticity on a pressure surface and $\zeta=(r \cos \varphi)^{-1}$ $(\partial v / \partial \lambda-\partial(u \cos \varphi) / \partial \varphi)$ is the relative vorticity in polar coordinates (longitude $\lambda$ and latitude $\varphi$ ). $\sigma$ is isentropic density $\left(\mathrm{kg} \mathrm{m}^{-2} \mathrm{~K}^{-1}\right)$ and $1 / \sigma=-g \partial \theta / \partial p=(1 / \rho) \partial \theta / \partial z$ is static stability. Geostrophic wind components, $u$ and $v$, are calculated at grid points from the LIMS V6 GPH fields. Then, daily values of the vertical component of PV are computed at each grid point from the zonal and meridional components of the wind ( $u$ and $v$ ), plus the local vertical gradients of potential temperature vs. pressure from V6, following Harvey et al. (2009). The white contour denotes the effective edge of the PV vortex, according to the objective criteria of Nash et al. (1996). High values of PV compare favorably with the regions in Fig. 12 of low temperature and geopotential height, low ozone, and high nitric acid. Fig. 15 shows there was transport of low PV air toward the pole near 0 and $230^{\circ} \mathrm{E}$; the vortex was nearly split on 17 January.

Figure 16 is a time series plot of PV at $550 \mathrm{~K}$ for $25 \mathrm{Oc}$ tober 1978 through 28 May 1979. The ordinate is given in terms of equivalent latitude $\varphi$ from the pole $\left(90^{\circ}\right)$ to $15^{\circ} \mathrm{N}$ and is based on a monotonic ordering of the daily LIMS PV from high values inside the polar vortex to low values outside the vortex (e.g., Butchart and Remsberg, 1986). Thus, equivalent latitude is a vortex centered coordinate that assigns the highest PV values (located in the center of the vortex) to be at $90^{\circ} \mathrm{N}$. The ordinate is linear in $\varphi$ to accentuate variations in the PV field at higher equivalent latitudes. Tic marks along the abscissa denote the middle of each month. Time series of the daily data are somewhat noisy (not shown), in part because the LIMS orbital measurements have a repeat cycle over a given latitude and longitude of 6 days. That sampling pattern means that only up to 6 zonal waves can be resolved from the data and that the daily character of the actual zonal waves may be aliased slightly (Remsberg et al., 1990). Therefore, a 7-day smoother was applied to the PV time series for Fig. 16 to minimize effects of that sampling bias.

The highest PV value is assigned the highest equivalent latitude in Fig. 16; high PV occurs in midwinter and defines the polar vortex. There was an increase of PV at the highest equivalent latitudes from late January and through February,

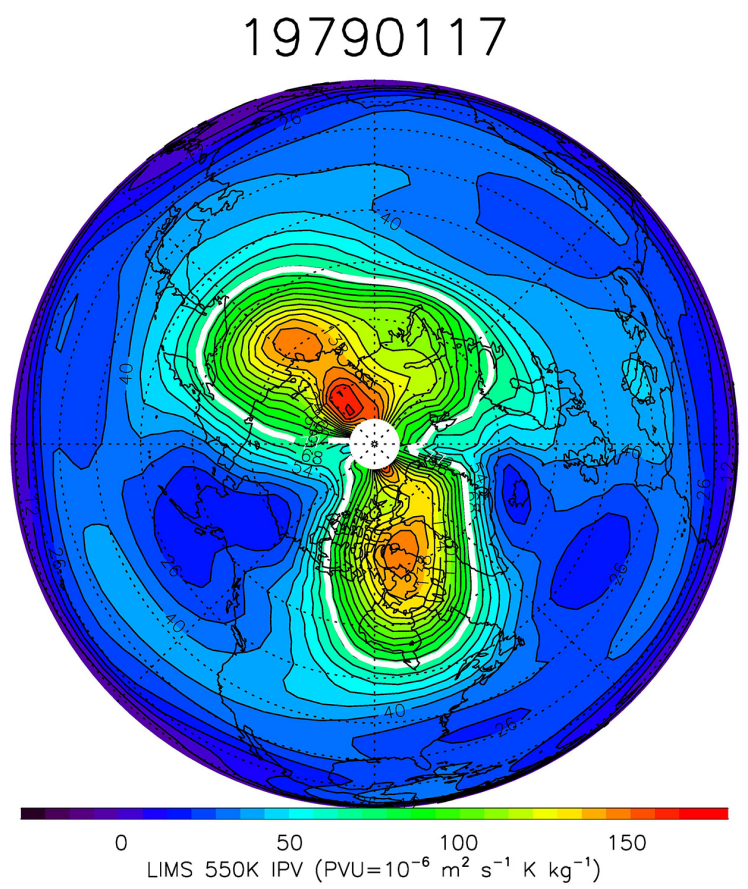

Figure 15. Isentropic potential vorticity (PV) at $550 \mathrm{~K}$ for 17 January 1979. Units of PV are in terms of $\left(10^{-6} \mathrm{~m}^{2} \mathrm{~s}^{-1} \mathrm{~K} \mathrm{~kg}^{-1}\right)$, and contour interval (CI) is 7 units. The thick white contour denotes the polar vortex edge as defined using Nash et al. (1996).

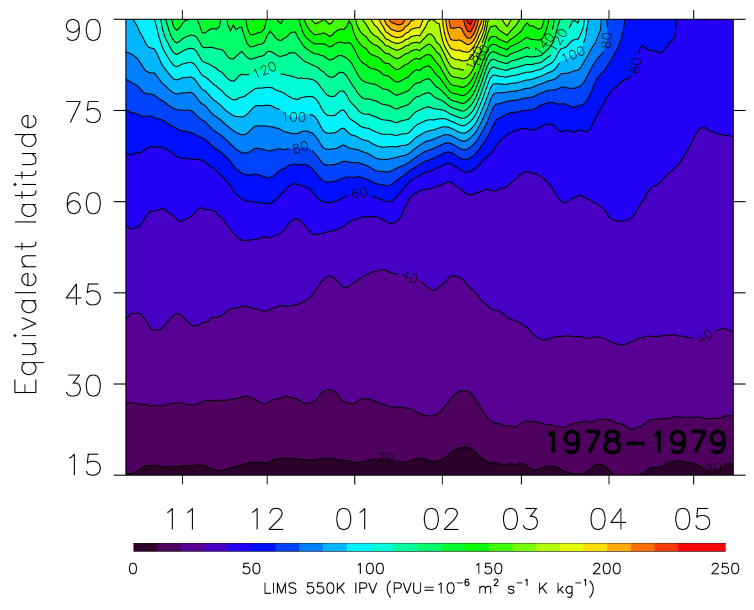

Figure 16. Time series of LIMS isentropic PV vs. equivalent latitude at $550 \mathrm{~K}$ and with smoothing over 7 days. PV contour interval (CI) is 10 units.

or at the times of the major and then the final SSW events. Highest PV values at those times are associated with the diabatic descent of higher PV values to the $550 \mathrm{~K}$ surface. It is noted that the vortex was split (wave-2) at four separate times at the pressure level of $31.6 \mathrm{hPa}$ : late October, late November/early December, late February, and in early April. Both zonal wave- 1 and wave- 2 are indicative of the effects of wave forcings as they propagate from the troposphere to the 
$31.6 \mathrm{hPa}$ level of the stratosphere. Large-scale anticyclones become amplified in winter and dominate the middle latitude stratosphere by springtime; zonal easterlies occur at lower latitudes thereafter. PV gradients were weaker at the mid latitudes by March, and there was erosion of high PV from then onward. That erosion is due to the actions of the large-scale planetary waves, while the adjacent regions of low PV are a result of the meridional mixing of PV from both the lower and higher latitudes (McIntyre and Palmer, 1983).

Nitric acid and ozone are effective tracers of motions in the lower stratosphere; isolines of their mixing ratios ought to be nearly parallel to those of PV. Averages of the $\mathrm{HNO}_{3}$ and of the ozone values along the PV contours are generated vs. $\varphi$ for each day, as determined for example around a daily PV contour in Fig. 15. Those averages represent approximate, modified Lagrangian means (MLM) of each species at $550 \mathrm{~K}$ in the manner of Butchart and Remsberg (1986). The 7-month evolution of the MLM for $\mathrm{HNO}_{3}$ is displayed in Fig. 17, and the contour patterns agree well with those of the PV tracer of Fig. 16. There is little to no indication of any contamination of the $\mathrm{HNO}_{3}$ due to PSCs on the $550 \mathrm{~K}$ surface. Nitric acid varies nearly monotonically in equivalent latitude and attains values near $12 \mathrm{ppbv}$ at the center of the vortex $\left(\varphi=90^{\circ}\right)$ upon the approach of winter and in polar night conditions. Such high values indicate a nearly complete chemical conversion of the available $\mathrm{NO}_{y}$ to its reservoir species $\mathrm{HNO}_{3}$. Poleward of about $\varphi=60^{\circ}$ the nitric acid contours are aligned well with those of PV, especially during the winter when further chemical conversions are not effective. The slow accumulation of $\mathrm{HNO}_{3}$ during the winter at middle equivalent latitudes $\left(\varphi=20\right.$ to $\left.45^{\circ}\right)$ indicates that there is significant transport of nitric acid from the polar region at the time of the large-scale zonal wave events. High $\mathrm{HNO}_{3}$ values that are representative of the polar winter vortex were eroded by early March. Thereafter, $\mathrm{HNO}_{3}$ decreases at all equivalent latitudes, due to the effects of the chemical re-partitioning of $\mathrm{NO}_{y}$ away from $\mathrm{HNO}_{3}$ and toward $\mathrm{NO}_{2}$ in the presence of sunlight.

There is also evidence that an uptake of $\mathrm{HNO}_{3}$ occurred from about 15-17 January and between 80 and $90^{\circ} \mathrm{N}$ of Figs. 16 and 17, where PV is increasing but there is a temporary decrease of $\mathrm{HNO}_{3}$ by about $1 \mathrm{ppbv}$ (orange to yellow in Fig. 17). This result is consistent with the visual finding of a local dip in $\mathrm{HNO}_{3}$ to less than 10 ppbv on 14-15 January in Figs. 11 and 14. Yet, because Fig. 17 is a plot of the average value of $\mathrm{HNO}_{3}$ around a PV contour (or the MLM) that decrease of $1 \mathrm{ppbv}$ represents a lower limit estimate for the localized uptake.

The time series of the MLM for ozone is shown in Fig. 18, and its isolines deviate appreciably at $550 \mathrm{~K}$ from those of PV. From late October to January, lowest values of ozone occur in the vortex, as expected. Relatively low values also occur in the tropics and subtropics for all months and are a result of the slow ascent of the Brewer/Dobson circulation. At about 20-22 January there is a small, isolated region of

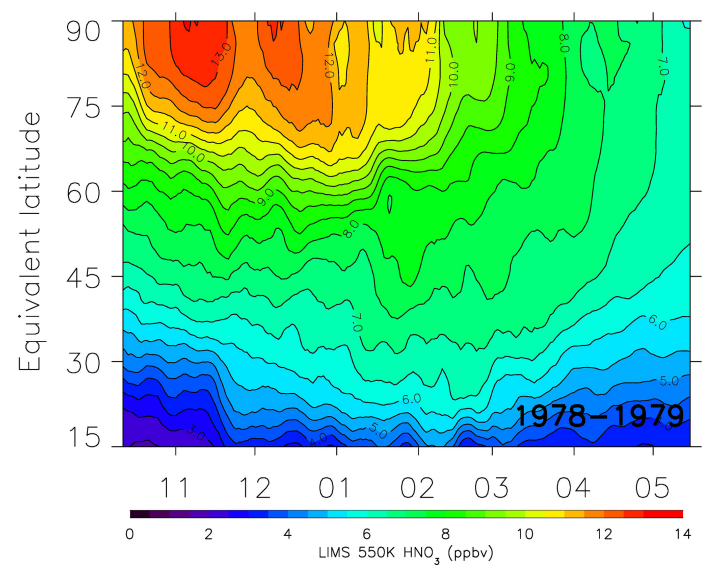

Figure 17. As in Fig. 16, but for $\mathrm{HNO}_{3}$ (CI is $0.5 \mathrm{ppbv}$ ).

high apparent ozone at $\varphi=90^{\circ}$ or near the center of the PV vortex that is due to the remnants of emissions from PSCs. Note that the high ozone in Fig. 11 that occurred near the Greenwich meridian or in the western hemisphere at the end of November, between the end of December and early January, and between 18 and 20 January is not visible in Fig. 18 due to averaging in equivalent latitude bins. Thus, the ability to see PSC effects in fields of ozone depends on how the data are displayed. Immediately following the time of the major wave-1 warming in late January, lower values of ozone that are characteristic of the center of the vortex are re-established at $\varphi=90^{\circ}$. Then, the ozone became larger across most latitudes from late January and until the mid-February final warming. The ozone maximum at middle equivalent latitudes of Fig. 18 differs clearly from the location of the maximum in PV at that time. Daily polar plots for late January/early February (not shown) reveal that, as wave- 2 increases, the mid-latitude anticyclone moves eastward from the African sector to the Aleutian sector and transports high ozone with it. Thus, higher ozone from lower latitudes is transported poleward as the isolated, Aleutian anticyclone is intensifying (see also Rood et al., 1993). Those regions of high ozone expand further to higher equivalent latitudes by mid-April, following the erosion of the vortex. The hemispheric ozone distributions of Fig. 18 exhibit a steady decline from midApril through May, due to the rather slow chemical loss processes that bring ozone back toward its equilibrium state.

Seasonal time series of $\mathrm{PV}, \mathrm{HNO}_{3}$, and ozone at $450 \mathrm{~K}$ $(\sim 46.4 \mathrm{hPa})$ are shown in Figs. $19-21$, respectively. Patterns of PV in Fig. 19 are similar to those at $550 \mathrm{~K}$, except for the smaller magnitudes of the isolines. The meridional gradient of $\mathrm{PV}$ is quite weak by midwinter for $\varphi$ values of 30 to $60^{\circ} \mathrm{N}$, and that character extends to the high latitudes by mid-April or after the air masses have undergone significant meridional mixing. Figure 20 for $\mathrm{HNO}_{3}$ shows that there are effects from remnants of PSCs at $450 \mathrm{~K}$ for several days in mid-January, but the magnitudes of those perturbing effects are small (10 


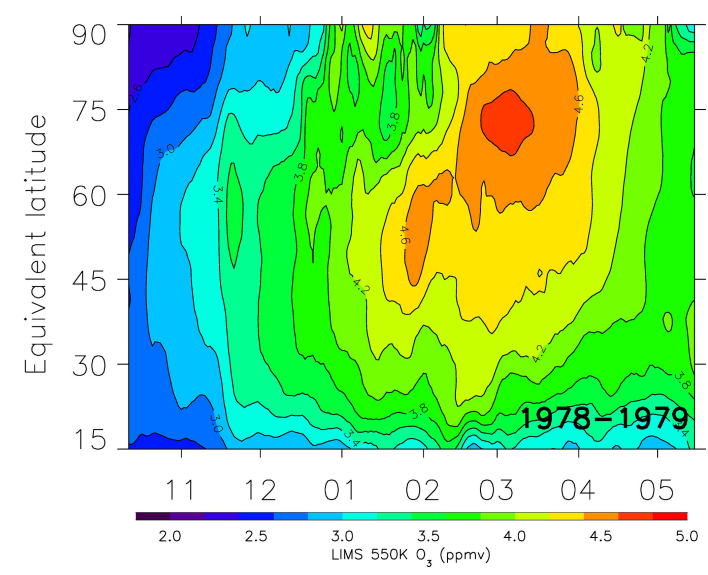

Figure 18. As in Fig. 16, but for ozone (CI is $0.2 \mathrm{ppmv}$ ).

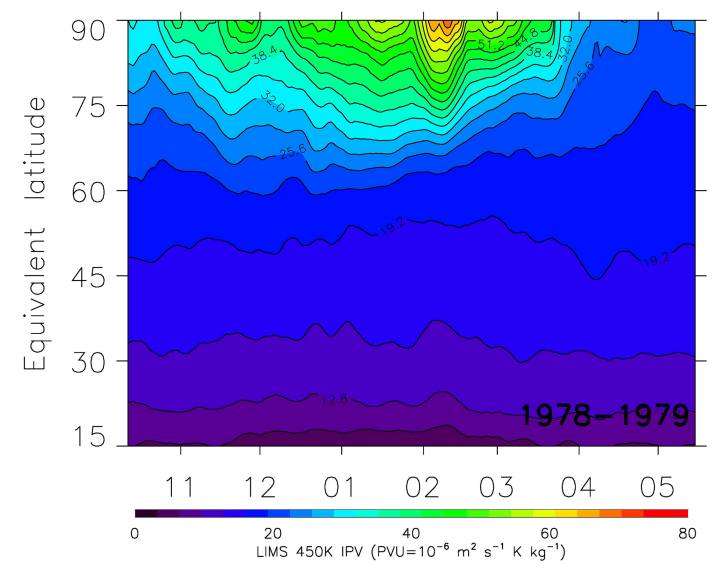

Figure 19. As in Fig. 16, but for PV vs. equivalent latitude at $450 \mathrm{~K}$ (CI is 3.2 units).

to $15 \%$ ). Nitric acid values exceed 9 ppbv near $\varphi=90^{\circ}$ in late November and early December, but they are typical of values in the polar vortex at that time. Finally, the isolines of ozone from $\varphi=60$ to $90^{\circ}$ in Fig. 21 follow a pattern similar to that of PV, indicating that ozone is an approximate tracer of the seasonal transport at $450 \mathrm{~K}$. Ozone increases at the middle equivalent latitudes from late autumn and through the winter, reflecting an accumulation of ozone in the lower stratosphere. Even though PSC effects tend to be obscured by the averaging of data into equivalent latitude bins, there is an increase in ozone in Fig. 21 by about $50 \%$ from 7-15 January due to remnants of PSCs at $\varphi=70$ to $90^{\circ}$. There was also transport of lower ozone values from $\varphi=70$ to $85^{\circ}$ for a week or two thereafter. Still, because of the PSC remnants it is difficult to resolve an uptake of $\mathrm{HNO}_{3}$ at $450 \mathrm{~K}$. From late February and onward there is good correspondence between ozone and PV at middle and high equivalent latitudes. Finally, while the meridional gradients for ozone are much weaker than for $\mathrm{HNO}_{3}$ near $\varphi=65^{\circ}$, their respective seasonal patterns remain similar to those of PV.

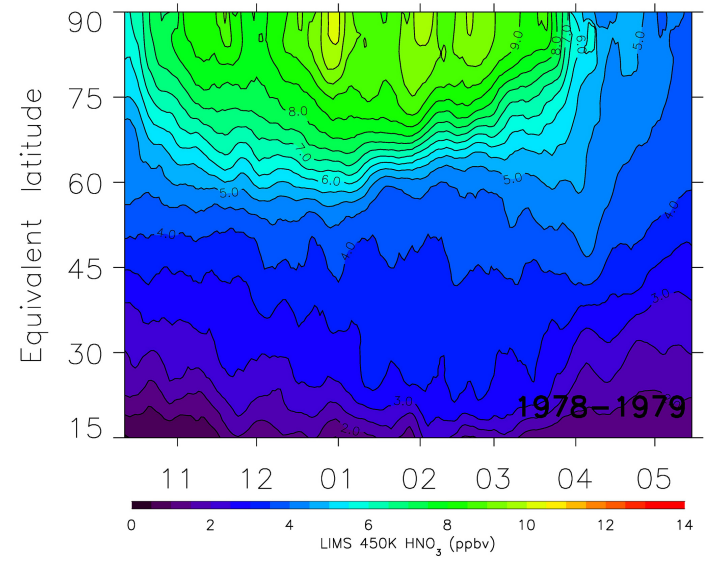

Figure 20. As in Fig. 17, but for $\mathrm{HNO}_{3}$ at $450 \mathrm{~K}$ (CI is $0.5 \mathrm{ppbv}$ ).

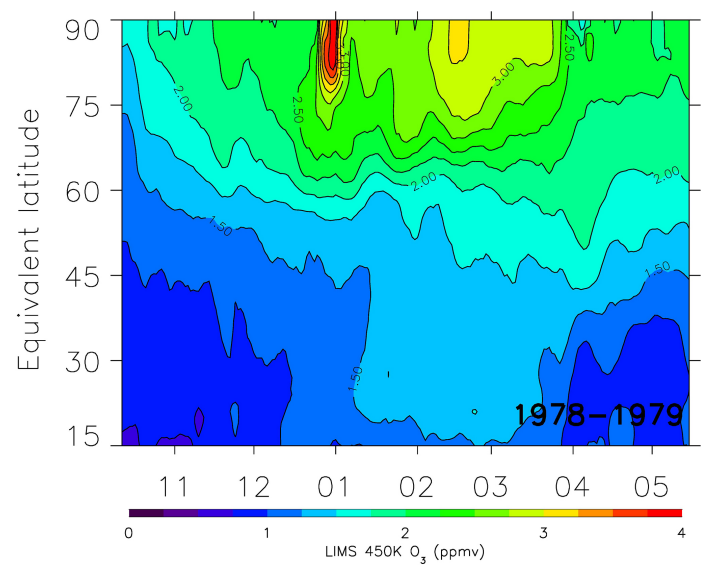

Figure 21. As in Fig. 18, but for ozone at $450 \mathrm{~K}$ (CI is $0.25 \mathrm{ppmv}$ ).

\section{Conclusions}

The primary findings about the occurrences of PSCs from the LIMS V6 data set are similar in many respects to those from the LIMS V5 data in Austin et al. (1986), who reported that the occasional Arctic PSC signatures occurred at temperatures less than $194 \mathrm{~K}$ but well above the saturation point with respect to water ice. Locations of the PSC signatures are determined more precisely with the V6 data because the V6 radiances were conditioned for instrument effects more carefully and the V6 retrievals for temperature and species were processed for every pair of profiles along the orbit. The resulting V6 profile points are also provided at more levels (at every $0.88 \mathrm{~km}$ in altitude). Two criteria were applied to automate and objectify the detection of effects of PSCs in the V6 ozone profiles. The primary criterion for sensing effects of PSCs is based on an increase of the retrieved ozone mixing ratio by at least $1.7 \mathrm{ppmv}$ over a decrease in altitude of $0.88 \mathrm{~km}$; that DIF criterion accounted for $96 \%$ of PSC sightings in the pressure range of 14.7 to $46.4 \mathrm{hPa}$. Profile segments that met the DIF threshold were screened from all 
the LIMS species. The remaining $4 \%$ of screenings are due to the ozone exceeding a ratio criterion (RTO) that may also be triggered due to normal, dynamically induced structures in the profiles. In fact, the RTO criterion was met more frequently at the lower levels of 52 to $100 \mathrm{hPa}$. During the testing of the screening criteria, it was found that tighter thresholds indicated more instances of PSC-like effects but also triggered the removal of more profile segments having vertical ozone structures in regions where the environmental temperatures were much too warm for the existence of PSCs. It is also concluded that a small percentage of the PSCs that were found are really "false positives".

The retrieved V6 temperature profiles were not screened, even though the co-located temperature profiles may be a degree or so too warm at the altitude of maximum perturbing effects of the PSCs in ozone. On the other hand, there is no evidence for a temperature bias at and above tops of PSCs. Minimum temperature values most often occurred just above tops of PSCs and with values between about 187 and 192 K. Such threshold temperatures indicate that the PSCs were composed of NAT mixtures or possibly STS droplets. The pressure range for the occurrence of tops of Arctic PSCs was from 21 to $28 \mathrm{hPa}$, on average, although there was a tendency for the PSCs to occur at higher pressures within the winter polar vortex over time. Temperature and geopotential height profiles and the LIMS Level 3 zonal coefficients derived from the mapping of them are judged as appropriate for calculations of stratospheric transport. Based on the findings of the analyses from LIMS V6, it is recommended that future stratospheric, limb-infrared ozone experiments ought to include a separate channel(s) for the detection of PSC/aerosol emissions, in order to screen out or to make first-order corrections for their effects in retrievals of ozone and other trace species (e.g., see Spang et al., 2016). In addition, the instruments ought to include a wide-band, $15 \mu \mathrm{m} \mathrm{CO}_{2}$ channel that is nearly insensitive to PSC/aerosol emissions, so that colocated temperature profiles will also be available with little to no bias.

The LIMS V6 rather than V5 data are more compatible with stratospheric data sets from recent satellite experiments. It is primarily for this reason that the V6 data have been included as part of the SPARC-Data Initiative. Although a small fraction of the $\mathrm{V} 6$ ozone, $\mathrm{H}_{2} \mathrm{O}$, and $\mathrm{NO}_{2}$ profiles may contain remnants of the effects of emissions from PSCs, the co-located, LIMS-retrieved $\mathrm{HNO}_{3}$ profiles are affected much less. Remnants of the effects of PSCs are found in the V6 ozone and $\mathrm{HNO}_{3}$ in mid-January and at equivalent latitudes poleward of $70^{\circ}$. Distributions of the V6 nitric acid and colocated temperatures were obtained for 5-day periods from 1-20 January, and they indicate uptake of $\mathrm{HNO}_{3}$ vapor by about 1 to 3 ppbv during that time. Based on modified Lagrangian mean diagnostics of $\mathrm{HNO}_{3}$ referenced to $\mathrm{PV}$ contours, it is also concluded that there was a lower limit uptake of $1 \mathrm{ppbv}$ for $\mathrm{HNO}_{3}$ or a temporary de-nitrification of the air during mid-January in the region of the polar vortex, when the temperatures were at or below $192 \mathrm{~K}$.

Seasonal time series of both ozone and $\mathrm{HNO}_{3}$ indicate significant meridional transport of the air about the vortex and between the middle latitudes and the pole, associated with zonal wave- 1 events of early December and of 14 to 27 January. In particular, there is a good correspondence for the time series of ozone and nitric acid vapor with that of potential vorticity on the $450 \mathrm{~K}(\sim 46.4 \mathrm{hPa})$ potential temperature surface. During late autumn and early winter both those species are also excellent tracers of the transport and mixing at $550 \mathrm{~K}(\sim 31.6 \mathrm{hPa})$. But by March it is clear that there was a significant accumulation of ozone at middle and higher equivalent latitudes at $550 \mathrm{~K}$. It is concluded that the V6 data provide accurate, associated temperature and GPH fields for conducting transport studies of that time period.

\section{Data availability}

The V6 data set (Remsberg, 2008, 2011) is archived at the Goddard Earth Sciences Data and Information Services Center (GES DISC and its website: http://daac.gsfc.nasa.gov) and is accessible for scientific use via ftp download.

Acknowledgements. The authors (EER and VLH) are grateful to R. Earl Thompson and to John Burton, B. Thomas Marshall, Praful Bhatt, Mark Melbert, and Larry Gordley for testing the LIMS V6 cloud and PSC detection algorithms and for processing the Level 2 data set, respectively. Gretchen Lingenfelser generated the LIMS V6 Level 3 product that is archived at NASA Goddard Space Flight Center (GES DISC). The analyses herein were motivated by an inquiry to the LIMS Science Team in 1986 from Paul Crutzen, who was hoping to find instances of nitric acid uptake using the LIMS V5 data set. The authors acknowledge, Lamont Poole, who carried out some specific calculations with his thermodynamic equilibrium model, showing the likelihood of nitric acid uptake for the conditions of the 1978-1979 Arctic winter. We relied on his results as a check on the conclusions herein about nitric acid uptake onto NAT mixtures and STS droplets. The authors appreciate the constructive comments of referee, John Austin, and of the other two anonymous referees. VLH acknowledges support from NASA LWS Grant NNX14AH54G and NSF CEDAR AGS grant no. 1343056. EER carried out his work while serving as a Distinguished Research Associate within the Science Directorate at NASA Langley.

Edited by: A. Sayer

\section{References}

Arnone, E., Castelli, E., Papandrea, E., Carlotti, M., and Dinelli, B. M.: Extreme ozone depletion in the 2010-2011 Arctic winter stratosphere as observed by MIPAS/ENVISAT using a 2D tomographic approach, Atmos. Chem. Phys., 12, 9149-9165, doi:10.5194/acp-12-9149-2012, 2012. 
Austin, J., Remsberg, E. E., Jones, R. L., and Tuck, A. F.: Polar stratospheric clouds inferred from satellite data, Geophys. Res. Lett., 13, 1256-1259, 1986.

Brasseur, G. P. and Solomon, S.: Aeronomy of the middle atmosphere, 3rd Edition, Springer, the Netherlands, 644 pp., 2005.

Butchart, N. and Remsberg, E. E.: The area of the stratospheric polar vortex as a diagnostic for tracer transport on an isentropic surface, J. Atmos. Sci., 43, 1319-1339, 1986.

Carslaw, K. S., Luo, B. P., and Peter, T.: An analytic expression for the composition of aqueous $\mathrm{HNO}_{3}-\mathrm{H}_{2} \mathrm{SO}_{4}$ stratospheric aerosols including gas phase removal of $\mathrm{HNO}_{3}$, Geophys. Res. Lett., 22, 1877-1880, 1995.

Carslaw, K. S., Wirth, M., Tsias, A., Luo, B. P., Dörnbrack, A., Leutbecher, M., Volkert, H., Renger, W., Bacmeister, J. T., and Peter, T.: Particle microphysics and chemistry in remotely observed mountain polar stratospheric clouds, J. Geophys. Res., 103, 5785-5796, 1998.

Crutzen, P. J. and Arnold, F.: Nitric acid cloud formation in the cold Antarctic stratosphere: a major cause for the springtime 'ozone hole', Nature, 324, 651-655, 1986.

Gille, J. C. and Russell III, J. M.: The limb infrared monitor of the stratosphere: experiment description, performance, and results, J. Geophys. Res., 89, 5125-5140, 1984.

Grewe, V. and Dameris, M.: Heterogeneous PSC ozone loss during an ozone mini-hole, Geophys. Res. Lett., 24, 2503-2506, 1997.

Hamill, P. and McMaster, L. R. (Eds.): Proceedings of a workshop on polar stratospheric clouds, their role in atmospheric processes, NASA/CR-2318-19840024881, available at: http://www. sti.nasa.gov (last access: 6 May 2015), 79 pp., 1984.

Hanson, D. and Mauersberger, K.: Laboratory studies of the nitric acid trihydrate: implications for the south polar stratosphere, Geophys, Res. Lett., 15, 855-858, 1988.

Harvey, V. L., Randall, C. E., and Hitchman, M. H.: Breakdown of potential vorticity-based equivalent latitude as a vortex-centered coordinate in the polar winter mesosphere, J. Geophys. Res., 114, D22105, doi:10.1029/2009JD012681, 2009.

Hoepfner, M., Blom, C. E., Fischer, H., Glatthor, N., Gulde, T., Piesch, C., Renger, W., and Wirth, M.: $\mathrm{HNO}_{3}$ and PSC measurements from the TRANSALL: sequestering of $\mathrm{HNO}_{3}$ in the winter of 1994/95, J. Atmos. Chem., 30, 61-79, 1998.

Höpfner, M., Luo, B. P., Massoli, P., Cairo, F., Spang, R., Snels, M., Di Donfrancesco, G., Stiller, G., von Clarmann, T., Fischer, H., and Biermann, U.: Spectroscopic evidence for NAT, STS, and ice in MIPAS infrared limb emission measurements of polar stratospheric clouds, Atmos. Chem. Phys., 6, 1201-1219, doi:10.5194/acp-6-1201-2006, 2006.

Hovmöller, E.: The trough-and-ridge diagram, Tellus, 1, 62-66, 1949.

Khosrawi, F., Urban, J., Pitts, M. C., Voelger, P., Achtert, P., Kaphlanov, M., Santee, M. L., Manney, G. L., Murtagh, D., and Fricke, K.-H.: Denitrification and polar stratospheric cloud formation during the Arctic winter 2009/2010, Atmos. Chem. Phys., 11, 8471-8487, doi:10.5194/acp-11-8471-2011, 2011.

Knudsen, B. M.: Accuracy of arctic stratospheric temperature analyses and the implications for the prediction of polar stratospheric clouds, Geophys. Res. Lett., 23, 3747-3750, 1996.

Leovy, C. B., Sun, C-R., Hitchman, M. H., Remsberg, E. E., Russell III, J. M., Gordley, L. L., Gille, J. C., and Lyjak, L. V.: Transport of ozone in the middle stratosphere: evidence for planetary wave breaking, J. Atmos. Sci., 42, 230-244, 1985.

List, R. J. (Ed.): Smithsonian Meteorological Tables, Smithsonian Institute, sixth revised edition, Washington, DC, 527 pp., doi:10.1002/qj.49707833627, 1951.

McCormick, M. P., Steele, H. M., Hamill, P., Chu, W. P., and Swissler, T. J.: Polar stratospheric cloud sightings by SAM II, J. Atmos. Sci., 39, 1387-1397, 1982.

McIntyre, M. E. and Palmer, T. N.: Breaking planetary waves in the stratosphere, Nature, 305, 593-600, 1983.

Nash, E. R., Newman, P. A., Rosenfield, J. E., and Schoeberl, M. R.: An objective determination of the polar vortex using Ertel's potential vorticity, J. Geophys. Res., 101, 9471-9478, 1996.

Pawson, S., Krueger, K., Swinbank, Bailey, M., and O'Neill, A.: Intercomparison of two stratospheric analyses: temperatures relevant to polar stratospheric cloud formation, J. Geophys. Res., 104, 2041-2050, 1999.

Peter, T. and Grooss, J.-U.: Polar stratospheric clouds and sulfate aerosol particles: microphysics, denitrification, and heterogeneous chemistry, Chapter 4 in Stratospheric Ozone Depletion and Climate Change, edited by: Müller, R., Royal Society of Chemistry (RSC) Publishing, doi:10.1039/978184973318200214, 2012.

Pitts, M. C., Poole, L. R., Dörnbrack, A., and Thomason, L. W.: The 2009-2010 Arctic polar stratospheric cloud season: a CALIPSO perspective, Atmos. Chem. Phys., 11, 2161-2177, doi:10.5194/acp-11-2161-2011, 2011.

Pitts, M. C., Poole, L. R., Lambert, A., and Thomason, L. W.: An assessment of CALIOP polar stratospheric cloud composition classification, Atmos. Chem. Phys., 13, 2975-2988, doi:10.5194/acp-13-2975-2013, 2013.

Remsberg, E.: LIMS/Nimbus-7 Level 2 Vertical Profiles of $\mathrm{O}_{3}$, $\mathrm{NO}_{2}, \mathrm{H}_{2} \mathrm{O}, \mathrm{HNO}_{3}$, Geopotential Height, and Temperature V006, version 006, Greenbelt, MD, USA, Goddard Earth Sciences Data and Information Services Center (GES DISC), available at: http: //disc.gsfc.nasa.gov/datacollection/LIMSN7L2_006.html, 2008.

Remsberg, E.: LIMS/Nimbus-7 Level 3 Daily 2 deg Latitude Zonal Fourier Coefficients of $\mathrm{O}_{3}, \mathrm{NO}_{2}, \mathrm{H}_{2} \mathrm{O}, \mathrm{HNO}_{3}$, Geopotential Height, and Temperature V006, version 006, Greenbelt, MD, USA, Goddard Earth Sciences Data and Information Services Center (GES DISC), available at: http://disc.gsfc.nasa.gov/ datacollection/LIMSN7L3_006.html, 2011.

Remsberg, E. and Lingenfelser, G.: LIMS Version 6 Level 3 dataset, NASA/TM-2010-216690, available at: http://www.sti.nasa.gov (last access: 6 May 2015), 13 pp., 2010.

Remsberg, E. E., Kurzeja, R. J., Haggard, K. V., Russell III, J. M., and Gordley, L. L.: Description of data on the Nimbus 7 LIMS map archive tape-ozone and nitric acid, NASA/TP-1986-2625, available at: http://www.sti.nasa.gov (last access: 6 May 2015), 71 pp., 1986.

Remsberg, E. E., Haggard, K. V., and Russell III, J. M.: Estimation of synoptic fields of middle atmosphere parameters from Nimbus-7 LIMS profile data, J. Atmos. Oceanic Tech., 7, 689705, 1990.

Remsberg, E. E., Gordley, L. L., Marshall, B. T., Thompson, R. E., Burton, J., Bhatt, P., Harvey, V. L., Lingenfelser, G., and Natarajan, M.: The Nimbus 7 LIMS version 6 radiance conditioning and temperature retrieval methods and results, J. Quant. Spectros. Ra., 86, 395-424, doi:10.1016/j.jqsrt.2003.12.007, 2004. 
Remsberg, E., Lingenfelser, G., Natarajan, M., Gordley, L., Marshall, B. T., and Thompson, E.: On the quality of the Nimbus 7 LIMS version 6 ozone for studies of the middle atmosphere, J. Quant. Spectros. Ra., 105, 492-518, doi:10.1016/j.jqsrt.2006.12.005, 2007.

Remsberg, E., Natarajan, M., Marshall, B. T., Gordley, L. L., Thompson, R. E., and Lingenfelser, G.: Improvements in the profiles and distributions of nitric acid and nitrogen dioxide with the LIMS version 6 dataset, Atmos. Chem. Phys., 10, 4741-4756, doi:10.5194/acp-10-4741-2010, 2010.

Rood, R. B., Douglass, A. R., Kaye, J. A., and Considine, D. B.: Characteristics of wintertime and autumn nitric acid chemistry as defined by limb infrared monitor of the stratosphere (LIMS) data, J. Geophys. Res., 98, 18533-18545, 1993.

Schlager, H. and Arnold, F.: Measurements of stratospheric gaseous nitric acid in the winter Arctic vortex using a novel rocket-borne mass spectrometric method, Geophys. Res. Lett., 17, 433-436, 1990.

Solomon, S., Kinnison, D., Bandora, J., and Garcia, R.: Simulation of polar ozone depletion: an update, J. Geophys. Res., 120, 79587974, doi:10.1002/2015JD023365, 2015.

Spang, R., Riese, M., and Offermann, D.: CRISTA-2 observations of the south polar vortex in winter 1997: a new dataset for polar process studies, Geophys. Res. Lett., 28, 3159-3162, 2001.
Spang, R., Remedios, J. J., Kramer, L. J., Poole, L. R., Fromm, M. D., Müller, M., Baumgarten, G., and Konopka, P.: Polar stratospheric cloud observations by MIPAS on ENVISAT: detection method, validation and analysis of the northern hemisphere winter 2002/2003, Atmos. Chem. Phys., 5, 679-692, doi:10.5194/acp-5-679-2005, 2005.

Spang, R., Hoffmann, L., Höpfner, M., Griessbach, S., Müller, R., Pitts, M. C., Orr, A. M. W., and Riese, M.: A multiwavelength classification method for polar stratospheric cloud types using infrared limb spectra, Atmos. Meas. Tech. Discuss., doi:10.5194/amt-2016-20, in review, 2016.

Tegtmeier, S., Hegglin, M. I., Anderson, J., Bourassa, A., Brohede, S., Degenstein, D., Froidevaux, L., Fuller, R., Funke, B., Gille, J., Jones, A., Kasai, Y., Krüger, K., Kyrölä, E., Lingenfelser, G., Lumpe, J., Nardi, B., Neu, J., Pendlebury, D., Remsberg, E., Rozanov, A., Smith, L., Toohey, M., Urban, J., von Clarmann, T., Walker, K. A., and Wang, R. H. J.: SPARC Data Initiative: A comparison of ozone climatologies from international satellite limb sounders, J. Geophys. Res., 118, 12229-12247, doi:10.1002/2013JD019877, 2013.

WMO (World Meteorological Organization): Scientific assessment of ozone depletion: 2014, Global Ozone Research and Monitoring Project, Report No. 55, Geneva, Switzerland, 2014. 